\title{
Quantifying the impact of groundwater depth on evapotranspiration in a semi-arid grassland region
}

\author{
M. E. Soylu ${ }^{1}$, E. Istanbulluoglu ${ }^{2}$, J. D. Lenters ${ }^{1}$, and T. Wang ${ }^{1,2, *}$ \\ ${ }^{1}$ School of Natural Resources, University of Nebraska-Lincoln, Lincoln, Nebraska, USA \\ ${ }^{2}$ Civil and Environmental Engineering, University of Washington, Seattle, Washington, USA \\ Received: 12 August 2010 - Published in Hydrol. Earth Syst. Sci. Discuss.: 14 September 2010 \\ Revised: 26 February 2011 - Accepted: 1 March 2011 - Published: 7 March 2011
}

\begin{abstract}
Interactions between shallow groundwater and land surface processes play an important role in the ecohydrology of riparian zones. Some recent land surface models (LSMs) incorporate groundwater-land surface interactions using parameterizations at varying levels of detail. In this paper, we examine the sensitivity of land surface evapotranspiration (ET) to water table depth, soil texture, and two commonly used soil hydraulic parameter datasets using four models with varying levels of complexity. The selected models are Hydrus-1D, which solves the pressure-based Richards equation, the Integrated Biosphere Simulator (IBIS), which simulates interactions among multiple soil layers using a (water-content) variant of the Richards equation, and two forms of a steady-state capillary flux model coupled with a single-bucket soil moisture model. These models are first evaluated using field observations of climate, soil moisture, and groundwater levels at a semi-arid site in south-central Nebraska, USA. All four models are found to compare reasonably well with observations, particularly when the effects of groundwater are included. We then examine the sensitivity of modelled ET to water table depth for various model formulations, node spacings, and soil textures (using soil hydraulic parameter values from two different sources, namely Rawls and Clapp-Hornberger). The results indicate a strong influence of soil texture and water table depth on groundwater contributions to ET. Furthermore, differences in texturespecific, class-averaged soil parameters obtained from the two literature sources lead to large differences in the simulated depth and thickness of the "critical zone" (i.e., the zone within which variations in water table depth strongly
\end{abstract}

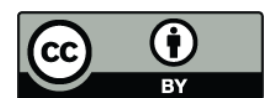

Correspondence to: M. E. Soylu (evren@huskers.unl.edu) impact surface ET). Depending on the depth-to-groundwater, this can also lead to large discrepancies in simulated ET (in some cases by more than a factor of two). When the Clapp-Hornberger soil parameter dataset is used, the critical zone becomes significantly deeper, and surface ET rates become much higher, resulting in a stronger influence of deep groundwater on the land surface energy and water balance. In general, we find that the simulated sensitivity of ET to the choice of soil hydraulic parameter dataset is greater than the sensitivity to soil texture defined within each dataset, or even to the choice of model formulation. Thus, our findings underscore the need for future modelling and field-based studies to improve the predictability of groundwater-land surface interactions in numerical models, particularly as it relates to the parameterization of soil hydraulic properties.

\section{Introduction}

Shallow groundwater in river valleys, riparian zones, and wetlands interacts with soil, vegetation, and climate through capillary rise and direct root water uptake from the water table, influencing land surface processes. Unlike deep water table conditions, a shallow groundwater table maintains elevated soil moisture in the root zone (Chen and $\mathrm{Hu}$, 2004). Since land surface processes (e.g., evapotranspiration, runoff, and infiltration) are strongly dependent on soil moisture, incorporating groundwater in land surface models (LSMs) is crucial for realistic representations of hydrologic processes in watersheds (Niu et al., 2007; Yeh and Eltahir, 2005; York, 2002; Maxwell and Kollet, 2008). Yet, little is known about the impacts of groundwater on land surface fluxes over different time and space scales. In the

Published by Copernicus Publications on behalf of the European Geosciences Union. 
absence of detailed field observations, numerical models are currently being used to explore the role of groundwater in simulated land surface fluxes (Fan et al., 2007; Liang et al., 2003; Maxwell et al., 2007).

In a shallow, unconfined aquifer, water can move upward from the water table to relatively drier soil surface layers through capillary flux. Quantifying capillary flux to the root zone depends on soil hydraulic properties, groundwater table depth, and the distribution of soil matric potential throughout the unsaturated zone. A number of approaches have been proposed to simulate this process in LSMs by linking the unsaturated zone with the water table. The majority of recent LSMs employ the Richards equation to simulate water movement in the unsaturated zone, while representing groundwater as a simple unconfined, lumped aquifer and treating the water table as a constant-head lower boundary condition by keeping lower soil layers saturated (Yeh and Eltahir, 2005; Niu et al., 2007; Fan et al., 2007). Maxwell and Miller (2005) presented a more complex modelling approach by integrating groundwater, subsurface flow, and overland flow processes in a coherent, numerical model framework. In their study, a groundwater flow model, ParFlow - which solves the Richards equation both in variably saturated and fully saturated conditions - was coupled to an LSM (the Community Land Model) to simulate the energy and water balance of the land surface. In a series of papers, Maxwell and co-workers (Maxwell and Miller, 2005; Kollet and Maxwell, 2008) illustrated how incorporating groundwater leads to more realistic patterns of soil moisture and runoff on the landscape. Using ParFlow, Ferguson and Maxwell (2010) recently showed that the sensitivity of hydrologic response to climate change is strongly related to the inherent feedbacks between groundwater and land surface processes, especially in regions with a shallow water table. Furthermore, the magnitude and seasonality of these feedbacks are also sensitive to the direction of climate change.

The Richards equation is the most widely accepted, physically based model used to simulate variably saturated flow in porous media:

$$
\frac{\partial \theta}{\partial t}=\frac{\partial}{\partial z}\left[K(h)\left(\frac{\partial h}{\partial z}+1\right)\right]-S,
$$

where $\theta$ is volumetric water content $\left[\mathrm{L}^{3} \mathrm{~L}^{-3}\right], K(h)$ is unsaturated hydraulic conductivity $\left[\mathrm{L} \mathrm{T}^{-1}\right], h$ is matric head [L], $z$ is the (positive upward) vertical coordinate [L], and $S$ is the rate of root water uptake $\left[\mathrm{L}^{3} \mathrm{~L}^{-3} \mathrm{~T}^{-1}\right]$. The Richards equation can be written in three basic forms: (1) a pressurebased form (i.e., $h$-based), (2) a volumetric water contentbased form (i.e., $\theta$-based), and (3) a mixed form, such as that shown in Eq. (1) or by Celia et al. (1990).

Solving the Richards equation requires the representation of $\theta$ and $K$ as functions of $h$ (Brooks and Corey, 1966; Clapp and Hornberger, 1978; van Genuchten, 1980; Rawls et al., 1982). However, due to the highly nonlinear nature of these functions, analytical solutions of the Richards equation only exist for very simplified boundary conditions and specific forms of the moisture-pressure relations (Zlotnik et al., 2007). Therefore, numerical techniques are needed to solve the Richards equation for more general applications (Warrick, 2003).

Many numerical studies have used either $h$-based or $\theta$ based forms of the Richards equation to describe water flow in the unsaturated zone (e.g. Hills et al., 1989; Kirkland et al., 1992). Overall, the numerical solution of the $\theta$-based Richards equation has been found to yield more accurate mass balance and computational efficiency in relatively dry soils and is, therefore, often preferred in most LSMs that neglect the role of groundwater (Dickinson et al., 1993; Sellers et al., 1996). However, application of the $\theta$-based form is problematic when dealing with saturated soil layers, since unlike pressure head - soil moisture does not vary within a homogeneous and inelastic saturated porous medium (Celia et al., 1990; Pan and Wierenga, 1995; Zeng and Decker, 2009; de Rooij, 2010). Nevertheless, the $\theta$-based form of the Richards equation has been used in some LSMs that incorporate groundwater (i.e., saturated soil layers) below the unsaturated zone (Kim and Eltahir, 2004; Yeh and Eltahir, 2005). Because of the various drawbacks of the $h$ - and $\theta$ based forms of the Richards equation, some studies have combined the two forms into one equation (e.g. Allen and Murphy, 1986; Celia et al., 1990). The mixed form of the Richards equation provides solutions in terms of pressure head, while conserving mass better than the $h$-based solution.

On the other end of the spectrum, simple analytical solutions have also been employed to couple groundwater and land surface processes in some LSMs. One such model is the Gardner-Eagleson (G-E) model that estimates a steady rate of capillary flux to the land surface based on the water table depth (Gardner, 1958; Eagleson, 1978; Famiglietti and Wood, 1994). The analytical form of the original G-E model is derived from the Darcy-Buckingham equation and is based on assumptions of steady-state capillary flux and a completely dry soil surface. The latter assumption can lead to over-predictions of the capillary flux, especially during wet periods, while the former assumption neglects changes in flux rates within the soil profile. These assumptions limit the general use of the analytical model, making numerical solutions preferable in many instances, such as time-varying simulations of land surface fluxes and soil moisture (Ridolfi et al., 2008; Laio et al., 2009).

Recently, models similar to the G-E model (with varying degrees of complexity) have been proposed to relax the dry soil assumption in the analytical solution. For example, Bogaart et al. (2008) offered a set of closed-form expressions, based on the Darcy-Buckingham equation, which accounts for both root-zone soil moisture and water table depth. Vervoort and van der Zee (2008) provide a piecewise linear equation for calculating soil water flux from the water table, which depends on the potential capillary flux and the 
Table 1. Soil hydraulic parameters used in the model simulations (see Sect. 2 for variable definitions).

\begin{tabular}{lcccccc}
\hline & $K_{\mathrm{S}}\left(\mathrm{m} \mathrm{day}^{-1}\right)$ & $\left|h_{\mathrm{ae}}\right|(\mathrm{cm})$ & $\phi$ & $b$ & $s_{\mathrm{w}}^{1}$ & $s *^{1}$ \\
\hline \multicolumn{6}{c}{ Clapp and Hornberger $(1978)$} \\
\hline Sand & 15.21 & 12.10 & 0.395 & 4.05 & 0.106 & 0.331 \\
Silt Loam & 0.62 & 78.60 & 0.485 & 5.30 & 0.304 & 0.727 \\
Silty Clay Loam & 0.15 & 35.60 & 0.477 & 7.75 & 0.373 & 0.675 \\
Clay & 0.11 & 40.60 & 0.482 & 11.40 & 0.522 & 0.782 \\
\hline \multicolumn{7}{c}{ Rawls et al. (1982) } \\
Sand & 5.20 & 7.26 & 0.437 & 1.69 & 0.007 & 0.109 \\
Silt Loam & 0.16 & 20.76 & 0.501 & 4.74 & 0.214 & 0.567 \\
Silty Clay Loam & 0.04 & 28.08 & 0.471 & 6.62 & 0.356 & 0.713 \\
Clay & 0.01 & 37.30 & 0.475 & 7.63 & 0.415 & 0.758 \\
\hline
\end{tabular}

${ }^{1}$ Parameters are calculated using soil water potentials from Laio et al. (2001).

actual evaporative demand. They then couple the equation to a stochastic soil moisture accounting model to provide continuous simulations of water table and land surface linkages. Similarly, Ridolfi et al. (2008) suggested an analytical framework to couple soil moisture dynamics and groundwater fluctuations under bare soil conditions, which was later extended to vegetated conditions by Laio et al. (2009).

Despite these previous efforts, there is still a limited amount of research assessing the utility of different numerical and analytical models for realistic representations of groundwater and land surface coupling. The current study investigates the impacts of different model parameterizations on our ability to quantify the role of groundwater in land surface processes. We also examine the sensitivity of the various models to soil texture and water table depth. Four models are selected for this study: (1) the Hydrus-1D model (Simunek et al., 2005), (2) the Integrated Biosphere Simulator (IBIS; Foley et al., 1996; Kucharik et al., 2000), and (3-4) two variants of the G-E model that are coupled with a buckettype soil moisture model using successive steady-state flux conditions. Model values for soil hydraulic parameters are obtained from two soil texture-based lookup tables that are commonly used by LSMs (Table 1), namely the parameter sets of Rawls et al. (1982) and Clapp and Hornberger (1978). These soil parameter datasets are hereafter referred to as R1982 and CH-1978, respectively.

Among the models selected for this study, Hydrus-1D has the most complex parameterization for the vertical movement of water for models that use the mixed ( $\theta$ - and $h$-based) form of the Richards equation. The IBIS model serves as an intermediate-complexity LSM with multiple buckets that exchange soil water based on the $\theta$-based Richards equation. Finally, the coupled G-E/single-bucket soil moisture model represents the simplest scenario by assuming steady-state conditions, rather than explicitly transient solutions. Lateral movement of water is not considered for any of the models used in this study. In what follows, we first describe each of the models, followed by a limited model verification study in a semi-arid region with a shallow groundwater table (southcentral Nebraska, USA). We then investigate and compare the sensitivity of the various models to water table depth, soil texture, soil hydraulic parameters, and node spacing. Finally, we discuss the results of the model simulations and suggest directions for future research.

\section{Model descriptions}

\subsection{Hydrus-1D model}

In this study, the Hydrus-1D model (Simunek et al., 2005) is selected to represent models that employ a one-dimensional, finite-element solution of the Richards equation (in the "mixed" form). Hydrus-1D has been previously verified using analytical solutions under certain boundary conditions (Zlotnik et al., 2007) and has also been successfully used in numerous studies for predicting observed evapotranspiration (ET) and soil moisture (e.g., Scott et al., 2000; Scanlon et al., 2002).

Hydrus-1D solves Eq. (1) for variably saturated flow in homogenous and rigid porous media. In solving Eq. (1), Hydrus-1D calculates the root water uptake term, $S(h)$, according to the method proposed by Feddes et al. (1978, p.20):

$S(h)=\mu(h) S_{\mathrm{p}}$,

where $S_{\mathrm{p}}$ is the potential root water uptake rate $\left[\mathrm{L}^{3} \mathrm{~L}^{-3} \mathrm{~T}^{-1}\right]$ (i.e., the potential volume of water removed from a unit volume of soil per unit time). When integrated over the rooting depth, $S_{\mathrm{p}}$ becomes identical to the potential rate of evapotranspiration $\left(\mathrm{ET}_{\mathrm{p}}\right)$ at the surface (assuming a fully vegetated surface with no intercepted or bare-soil evaporation). The term $\mu(h)$ is a dimensionless, prescribed function of pressure head 
$(0 \leq \mu(h) \leq 1)$ which introduces soil moisture limitation to the uptake of water by roots:

$\mu(h)= \begin{cases}0 & h \leq h_{\mathrm{w}} \\ \left(\frac{h-h_{\mathrm{w}}}{h^{*}-h_{\mathrm{w}}}\right) & h_{\mathrm{w}}<h \leq h^{*}, \\ 1 & h^{*}<h\end{cases}$

where $h_{\mathrm{w}}$ and $h^{*}$ are pressure heads at the wilting point and drought-induced incipient stomata closure point, respectively. Below $h_{\mathrm{w}}$, plants cannot extract water, and $\mu(h)$ equals zero. Between $h_{\mathrm{w}}$ and $h^{*}$, root water uptake is limited by soil moisture and increases linearly with pressure head as the soil gets wetter. Above $h^{*}$, plant transpiration (and likewise the root water uptake) is not constrained by soil moisture.

In order to run Hydrus-1D, lower and upper boundary conditions need to be specified for the finite-element solution scheme. The lower boundary condition is set as free drainage (i.e., "no groundwater") or as a constant pressure head to represent the groundwater table. The upper boundary condition, on the other hand, is specified by atmospheric factors, namely precipitation input and evaporative demand. Surface runoff occurs when the precipitation rate exceeds the soil infiltration capacity. More specifically, the upper boundary condition is obtained by applying the following two limiting conditions at the soil surface (Neuman et al., 1974):

$\left|K(h)\left(\frac{\partial h}{\partial z}+1\right)\right| \leq\left|E_{\max }\right| \quad$ at $z=0$,

and

$h_{\min } \leq h \leq 0 \quad$ at $z=0$

where $E_{\max }\left[\mathrm{L} \mathrm{T}^{-1}\right]$ is the maximum potential rate of evapotranspiration $\left(\mathrm{ET}_{\mathrm{p}}\right)$ or infiltration $\left(I_{\max }\right)$ under the current atmospheric conditions, and $h_{\min }$ is the minimum pressure head [L] allowed at the soil surface. This upper boundary condition can switch from a prescribed flux to a prescribed pressure head to ensure that the two limiting conditions in Eq. (4) are met (Simunek et al., 2005).

In all of the model simulations used in this study, the $\mathrm{CH}$ 1978 soil parameter functions are used to relate soil water content to pressure head and unsaturated hydraulic conductivity (with $h<h_{\mathrm{ae}}<0$ for unsaturated conditions):

$h(\theta)=h_{\mathrm{ae}}\left(\frac{\theta}{\theta_{\mathrm{s}}}\right)^{-\mathrm{b}}$,
$K(\theta)=K_{\mathrm{s}}\left(\frac{\theta}{\theta_{\mathrm{s}}}\right)^{2 \mathrm{~b}+3}$,

where $\theta_{\mathrm{s}}$ is the saturated volumetric water content $\left[\mathrm{L}^{3} \mathrm{~L}^{-3}\right]$ (also equal to porosity), $h_{\mathrm{ae}}$ is the air entry (bubbling) pressure [L], $K_{\mathrm{S}}$ is saturated hydraulic conductivity $\left[\mathrm{L} \mathrm{T}^{-1}\right]$, and $b=\lambda^{-1}$ is a soil index (with $\lambda$ being equal to the pore size distribution index; Brooks and Corey, 1966).

\subsection{Integrated Biosphere Simulator (IBIS)}

IBIS is a dynamic global vegetation model (DGVM) that integrates various terrestrial ecosystem processes within a single, physically consistent framework (Foley et al., 1996). IBIS simulates the land surface energy, water, and carbon balance, vegetation dynamics and phenology, and canopy physiology (Foley et al., 1996; Kucharik et al., 2000; Lenters et al., 2000; Li et al., 2005). Here we discuss the components of IBIS that are most relevant to the focus of this paper.

The land surface transfer scheme (LSX) of Pollard and Thompson (1995) is used within IBIS to model exchanges of momentum, energy, and water mass in the soil-vegetationatmosphere continuum (Thompson and Pollard, 1995a,b). In its standard version, IBIS simulates energy and water exchange in two canopy layers (upper and lower), three snow layers, and 11 soil layers with varying thicknesses. Hourly meteorological inputs include air temperature, relative humidity, incoming solar radiation, precipitation, and wind speed. The soil sub-model in IBIS simulates soil temperature, water content, and ice content in each of the 11 soil layers and solves the $\theta$-based form of the Richards equation:

$\frac{\partial \theta}{\partial t}=\frac{\partial}{\partial z}\left(D(\theta) \frac{\partial \theta}{\partial z}\right)+\frac{\partial K(\theta)}{\partial z}-S$,

where $D(\theta)=K(h)(\partial h / \partial \theta)$ is the moisture diffusivity $\left[\mathrm{L}^{2} \mathrm{~T}^{-1}\right]$.

For a given soil layer, $i$, the root water uptake term, $S_{i}$, is calculated from plant transpiration according to:

$S_{i}=T F_{i}$,

where $T$ is the sum of the upper and lower canopy transpiration $\left[\mathrm{L}^{3} \mathrm{~L}^{-3} \mathrm{~T}^{-1}\right]$, and $F_{i}$ is the water uptake fraction $[-]$, which is a function of root distribution and soil water content:

$F_{i}=\frac{R_{i} A_{i}}{\sum_{i} R_{i} A_{i}}$.

$R_{i}$ is the root biomass in soil layer $i$, and $A_{i}$ is a stress factor related to soil water availability:

$A_{i}=1-\frac{\ln \left(1+799 \exp \left[-12 \cdot \theta_{\mathrm{a}}\right]\right)}{\ln (800)}$

$\theta_{\mathrm{a}}$ is the plant available water fraction and is calculated in each soil layer as:

$\theta_{\mathrm{a}}=\frac{\theta-\theta_{\mathrm{w}}}{\theta_{\mathrm{fc}}-\theta_{\mathrm{w}}}$

where $\theta$ is volumetric water content $\left[\mathrm{L}^{3} \mathrm{~L}^{-3}\right], \theta_{\mathrm{w}}$ is the wilting point $\left[\mathrm{L}^{3} \mathrm{~L}^{-3}\right]$, and $\theta_{\mathrm{fc}}$ is field capacity $\left[\mathrm{L}^{3} \mathrm{~L}^{-3}\right]$.

The transpiration functions in IBIS are based on the work of Pollard and Thompson (1995):

$T_{\mathrm{u}}=\frac{\rho C_{\mathrm{u}}}{\left(1+r_{\mathrm{u}} C_{\mathrm{u}}\right)}\left(1-f_{\mathrm{u}}^{\mathrm{wet}}\right)\left(q_{\mathrm{sat}}\left(L_{\mathrm{u}}\right)-q_{\mathrm{u}}\right) \mathrm{LAI}_{\mathrm{u}}$, 
$T_{1}=\frac{\rho C_{1}}{\left(1+r_{1} C_{1}\right)}\left(1-f_{1}^{\mathrm{wet}}\right)\left(q_{\mathrm{sat}}\left(L_{1}\right)-q_{1}\right) \mathrm{LAI}_{1}$,

where the subscripts $u$ and $l$ represent the upper and lower canopy, respectively, $\rho$ is the density of near-surface air $\left[\mathrm{ML}^{-3}\right]$, and $f_{\mathrm{u} / 1}^{\mathrm{wet}}=\min \left(0.8, W_{\mathrm{u} / 1} / W_{\mathrm{u} / 1}^{\max }\right)$ is the fraction of leaf area wetted by intercepted water or snow (where $W$ is the intercepted liquid or snow on a unit leaf/stem area $\left.\left[\mathrm{ML}^{-2}\right]\right)$. Other variables in Eq. (11) include leaf temperature, $L$ (in ${ }^{\circ} \mathrm{C}$ ), as well as the heat/vapor transfer coefficient between canopy and air $C\left[\mathrm{~L} \mathrm{~T}^{-1}\right]$, calculated as $C_{\mathrm{u} / 1}+\delta \sqrt{U_{\mathrm{u} / 1} / \varepsilon}$, where $\delta=0.01 \mathrm{~m} \mathrm{~s}^{-0.5}, U$ is wind speed $\left[\mathrm{m} \mathrm{s}^{-1}\right]$, and $\varepsilon=0.01 \mathrm{~m}$ is the fetch length for leaves and stems. Finally, $q_{\text {sat }}$ is the saturation specific humidity at the leaf temperature $\left[\mathrm{M} \mathrm{M}^{-1}\right], q$ is the ambient specific humidity within the canopy $\left[\mathrm{M} \mathrm{M}^{-1}\right], \mathrm{LAI}$ is the single-sided canopy leaf area index $\left[\mathrm{L}^{2} \mathrm{~L}^{-2}\right]$, and $r$ is the stomatal resistance per unit leaf area $\left[\mathrm{TL}^{-1}\right]$, which is a function of photosynthetically active radiation, temperature, vapour pressure deficit, and available soil water content. Total "actual" ET is calculated as the sum of: (1) total transpiration $\left(T=T_{\mathrm{u}}+T_{1}\right)$, (2) evaporation of water intercepted by vegetation, and (3) evaporation of water from the soil surface (Pollard and Thompson, 1995).

The upper boundary in the IBIS soil model is specified by an infiltration rate that is equal to the water throughfall rate (plus snowmelt) minus evaporation. If the upper soil layer is saturated, or throughfall minus evaporation exceeds the maximum possible infiltration rate, then a surface "puddle" accumulates to a maximum depth, beyond which surface runoff occurs. IBIS does not explicitly represent water table dynamics. Instead, the lower boundary condition is allowed to vary from $100 \%$ free drainage to zero flux (or anywhere in between, based on an empirical coefficient ranging from 0 to 1 ). In this study, representation of groundwater as a lower boundary condition is required in order to determine the groundwater contribution to surface ET. To do so, the bottom flux boundary condition in IBIS is changed to a fixed soil moisture boundary condition by forcibly saturating the soil layers below the top of the capillary fringe. Yeh and Eltahir (2005) applied a similar adjustment to the IBIS model to incorporate the influence of groundwater. In the current study, the average thickness of the capillary fringe for sand, silt loam, silty clay loam, and clay was set to $5 \mathrm{~cm}, 32.5 \mathrm{~cm}$, $45 \mathrm{~cm}$, and $32.5 \mathrm{~cm}$, respectively. This is based on the work of Mausbach (1992), who reported these values for wet soil environments and over a narrower range than the air-entry values of CH-1978 and R-1982 (which are listed in Table 1).

The "default" soil depth $(250 \mathrm{~cm})$ and soil layer thicknesses in IBIS are meant to coincide with the CONUS-Soil dataset, which is based on the USDA State Soil Geographic Database (STATSGO). As a result, the standard thicknesses of the 11 soil layers are $5 \mathrm{~cm}$ (layers 1 and 2), $10 \mathrm{~cm}$ (layers 3-5), $20 \mathrm{~cm}$ (layers 6-8), and $50 \mathrm{~cm}$ (layers 9-11). These intervals are too coarse to capture some of the finer soil moisture gradients and changes in groundwater level that are examined in this study. To overcome this limitation, as well as to ensure that the IBIS simulations are directly compatible with the smaller node spacing of the Hydrus-1D simulations, we changed the soil layer thicknesses in IBIS to a fixed 2.5$\mathrm{cm}$ interval throughout the soil column (100 layers total, to a depth of $250 \mathrm{~cm}$ ).

\subsection{Coupled root-zone and steady-state capillary flux models}

\subsubsection{Gardner-Eagleson (G-E) model}

The G-E model offers an analytical solution to calculate a constant rate of capillary flux from the water table to the unsaturated zone under steady-state soil moisture conditions (i.e., $\partial \theta / \partial t=0)$. The derivation of the G-E model was first given by Gardner (1958) and later modified by Eagleson (1978). Neglecting root water uptake, the vertical capillary flux, $v\left[\mathrm{~L} \mathrm{~T}^{-1}\right]$ (positive upwards), can be calculated from Eq. (1) to form the Darcy-Buckingham equation:

$v=-K(h)\left(\frac{\partial h}{\partial z}+1\right)=K(\psi)\left(\frac{\partial \psi}{\partial z}-1\right)$,

where $\psi=-h=|h|$ is the soil suction head in the unsaturated zone (since $h<0$ ). Equation (12) can be rearranged and integrated from the water table depth to the upper boundary at the soil surface (or the root zone) to solve for $Z_{\mathrm{gw}}$, the depthto-groundwater:

$Z_{\mathrm{gw}}=\int_{0}^{\psi_{\mathrm{u}}} \frac{d \psi}{1+(v / K(\psi))}$,

where $\psi_{\mathrm{u}}$ is the soil suction head at the upper boundary [L]. In order to solve Eq. (13), Gardner (1958) used the empirical expression $K(\psi)=a /\left(\psi^{n}+c\right)$, where $a, n$, and $c$ are constants, and $n$ was varied over a range of 1 to 4 (Gardner, 1958). Neglecting $c$, which is small compared to $\psi^{n}$, it can be shown from Eq. (5) that $a=K_{\mathrm{S}}\left|h_{\mathrm{ae}}\right|^{n}$, and that $n$ is related to the pore size distribution index through $n=2+3 \lambda=2+3 / b$. Thus, $K(\psi)$ reduces to the form of Brooks and Corey (1966) and Campbell (1974):

$K(\psi)=K_{\mathrm{s}}\left(\frac{\left|h_{\mathrm{ae}}\right|}{\psi}\right)^{n}$.

Substituting Eq. (14) into Eq. (13) yields:

$Z_{\mathrm{gw}}=\int_{0}^{\psi_{\mathrm{u}}} \frac{d \psi}{1+\alpha \psi^{n}}$,

where

$\alpha=\frac{v}{K_{\mathrm{s}}\left|h_{\mathrm{ae}}\right|^{n}}$.

Under the assumption of constant capillary flux $(v)$, Gardner (1958) showed that Eq. (15) can be solved analytically for certain $n$ values. One such analytical solution 
arises under the assumption of a completely dry soil surface (i.e. $\psi_{\mathrm{u}} \rightarrow$ inf), which results in a strong upward gradient and the following equation for capillary flux:

$v=B K_{\mathrm{s}}\left(\frac{\left|h_{\mathrm{ae}}\right|}{Z_{\mathrm{gw}}}\right)^{n}$,

where $B$ is a parameter that depends solely on the value of $n$ and is often taken from a lookup table. Values of $B$ from Gardner (1958) are listed in Table 2.

In addition to the solution of Gardner (1958) and Ripple et al. (1972) suggested various graphical solutions to Eq. (15), and Anat et al. (1965) developed some approximate solutions in the case of $n>1$. Warrick (1988) extended the analytical solutions of Eq. (13) for various $n$ values using the Brooks-Corey retention curve model. However, these solutions cannot be explicitly written in terms of $v\left(h_{\mathrm{ae}}, Z_{\mathrm{gw}}\right)$ and $\psi\left(v, Z_{\mathrm{gw}}\right)$. An approximate analytical model based on the results of Gardner (1958) was presented by Eagleson (1978) and later modified by Salvucci (1993). Eagleson (1978) suggested a continuous relationship to extend $B$ over the full range of soil index values using the following empirical function:

$B=1+\frac{3}{2(n-1)}$.

Substituting Eq. (17) and $n=2+3 / b$ into Eq. (16) yields the "original G-E model" form of the capillary flux that is used in this paper:

$v=K_{\mathrm{s}}\left[1+\frac{3}{(2+6 / b)}\right]\left(\frac{\left|h_{\mathrm{ae}}\right|}{Z_{\mathrm{gw}}}\right)^{2+3 / \mathrm{b}}$

It is important to note here that in Eq (18), the soil surface is assumed to be dry ( $\psi_{\mathrm{u}} \rightarrow$ inf). To allow continuous modelling of soil moisture and ET under varying atmospheric evaporative demand and groundwater table elevations, the original G-E model (Eq. 18) and a modified form of the G-E model are coupled to a bucket-type vadose zone hydrology model. In the "modified G-E model," instead of assuming a dry soil surface, we use the actual (depth-averaged) soil moisture in the root zone. For this purpose, the soil suction head used as the upper limit of the integral in Eq. (15) is calculated by solving Eq. (5a) for $|h|$ using the depth-averaged, root-zone soil moisture. This modification requires the integration of Eq. (15), which does not have a general analytical solution. Therefore, we use the composite trapezoidal rule to numerically integrate Eq. (15) and thereby calculate the capillary flux to the root zone.

\subsubsection{Bucket hydrology model}

Both forms of the G-E capillary flux model are coupled to a leaky bucket-type hydrology model by adding the steadystate groundwater capillary flux to the root zone at each time step of the model iteration, similar to Brolsma and
Table 2. $B$ values used by Gardner (1958) for determining capillary flux as a function of soil index, $n$ (see Eq. 16). The analytical solution of Gardner (1958) assumes a completely dry surface, and the $B$ values listed here are similar to those calculated by means of Eq. (17) (which is used in the G-E model).

\begin{tabular}{cc}
\hline$n$ & $B$ \\
\hline $3 / 2$ & 3.77 \\
2 & 2.46 \\
3 & 1.76 \\
4 & 1.52 \\
\hline
\end{tabular}

Bierkens (2007). The rate of change in the depth-averaged soil moisture in the root zone is calculated according to:

$\phi Z_{\mathrm{r}} \frac{d s}{d t}=I-\operatorname{ET}_{\mathrm{a}}(s)-L_{\mathrm{r}}(s)+v\left(s, Z_{\mathrm{gw}}\right)$,

where $\varphi\left(=\theta_{\mathrm{S}}\right)$ is porosity $\left[\mathrm{L}^{3} \mathrm{~L}^{-3}\right], Z_{\mathrm{r}}$ is rooting depth [L], $s=\theta / \theta_{\mathrm{S}}[-]$ is the degree of saturation within $Z_{\mathrm{r}}, I$ is infiltration rate $\left(\mathrm{L} \mathrm{T}^{-1}\right), \mathrm{ET}_{\mathrm{a}}$ is actual $\mathrm{ET}\left(\mathrm{L} \mathrm{T}^{-1}\right)$, and $L_{\mathrm{r}}$ is leakage from the root zone $\left(\mathrm{L} \mathrm{T}^{-1}\right)$. (Note that the capillary flux into the root zone, $v$, is independent of $s$ for the case of the "original" G-E model, as given by Eq. 18.) The infiltration rate is defined as:

$I= \begin{cases}\min \left[P_{\mathrm{r}}, K_{\mathrm{s}}\right] & P_{\mathrm{t}}>C_{\mathrm{int}} \\ 0 & P_{\mathrm{t}} \leq C_{\mathrm{int}},\end{cases}$

where $P_{r}$ is rainfall rate $\left[\mathrm{L} \mathrm{T}^{-1}\right], P_{\mathrm{t}}$ is total cumulative rainfall [L] during a given rain event, and $C_{\text {int }}$ is canopy interception [L]. Runoff is generated when rainfall rate exceeds $K_{\mathrm{s}}$ and the canopy can no longer intercept additional precipitation.

Leakage from the root zone is calculated according to Campbell (1974):

$L_{\mathrm{r}}(s)= \begin{cases}0 & s \leq s_{\mathrm{fc}} \\ K_{\mathrm{S}} s^{2 \mathrm{~b}+3} & s_{\mathrm{fc}}<s \leq 1,\end{cases}$

where $s_{\mathrm{fc}}$ is the degree of soil saturation at field capacity. $\mathrm{ET}_{\mathrm{a}}$ is calculated by reducing the potential ET rate by a soil moisture limitation function similar to that described in Eq. (3) (see also Laio et al., 2001):

$\operatorname{ET}_{\mathrm{a}}(s)=\left\{\begin{array}{ll}0 & s \leq s_{\mathrm{W}} \\ \operatorname{ET}_{\mathrm{p}}\left(\frac{s-s_{\mathrm{W}}}{s^{*}-s_{\mathrm{W}}}\right) & s_{\mathrm{W}}<s \leq s^{*}, \\ \operatorname{ET}_{\mathrm{p}} & s^{*}<s<1\end{array}\right.$,

where $s_{\mathrm{W}}$ and $s^{*}$ are the degree of soil saturation at the wilting point and at the threshold for incipient stomata closure, respectively. In the application of the bucket model, $\mathrm{ET}_{\mathrm{p}}$ is estimated from the Priestley-Taylor equation (Priestley and Taylor, 1972).

As noted earlier, two forms of the G-E model are used in this study. In the first application, we use the original G-E 
Table 3. Model characteristics, boundary conditions, and experimental design for the model-observation evaluation period (i.e., short-term simulations) and the model sensitivity experiments (i.e., long-term simulations). See Sect. 3 for further details.

\begin{tabular}{|c|c|c|c|c|c|c|c|c|c|c|}
\hline Model & $\begin{array}{l}\text { Time } \\
\text { Step }\end{array}$ & $\begin{array}{l}\text { Lower } \\
\text { Boundary }\end{array}$ & $\begin{array}{c}\text { Upper } \\
\text { Boundary }\end{array}$ & Domain & $\begin{array}{l}\text { Soil } \\
\text { Depth }\end{array}$ & $\begin{array}{l}\text { Simulation } \\
\text { Length }\end{array}$ & $\begin{array}{l}\mathrm{ET}_{\mathrm{p}} \\
\text { Calculation }\end{array}$ & $\begin{array}{l}\text { Node } \\
\text { Spacing }\end{array}$ & $\begin{array}{c}\text { Soil Parameter } \\
\text { Dataset }\end{array}$ & $\begin{array}{l}\text { Water Table } \\
\text { Increments }\end{array}$ \\
\hline \multicolumn{11}{|c|}{ Model evaluation experiments (Short-term simulations; Fig. 3) } \\
\hline Hydrus-1D & Hourly & $\begin{array}{l}\text { Free drainage or } \\
\text { constant pressure } \\
\text { head }\end{array}$ & \multirow{3}{*}{ 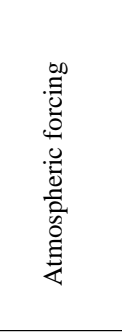 } & \multirow{3}{*}{ 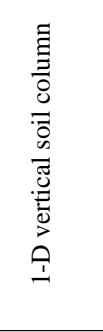 } & $250 \mathrm{~cm}$ & 5 months & $\begin{array}{l}\text { Priestley- } \\
\text { Taylor }\end{array}$ & $2.5 \mathrm{~cm}$ & \multirow{3}{*}{$\frac{\mathscr{\infty}}{\stackrel{2}{\alpha}}$} & 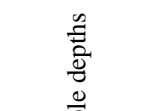 \\
\hline $\begin{array}{l}\text { G-E bucket } \\
\text { models }\end{array}$ & Daily & $\begin{array}{l}\text { Free drainage or } \\
\text { constant capillary } \\
\text { flux }\end{array}$ & & & N/A & 5 months & $\begin{array}{l}\text { Priestley- } \\
\text { Taylor }\end{array}$ & N/A & & 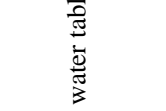 \\
\hline IBIS & Hourly & $\begin{array}{l}\text { Free drainage or } \\
\text { constant soil } \\
\text { water content }\end{array}$ & & & $250 \mathrm{~cm}$ & 5 months & N/A & $2.5 \mathrm{~cm}$ & & $\begin{array}{l}\vec{D} \\
\sum_{0}^{D} \\
00 \\
0\end{array}$ \\
\hline \multicolumn{11}{|c|}{ Model sensitivity experiments (Long-term simulations; Figs. 4, 5, and 6) } \\
\hline Hydrus-1D & Daily & $\begin{array}{l}\text { Constant pressure } \\
\text { head }\end{array}$ & \multirow{4}{*}{$\begin{array}{l}00 \\
.0 \\
0 \\
0 \\
0 \\
0 \\
0 \\
0 \\
0 \\
0 \\
0 \\
0 \\
0\end{array}$} & \multirow{4}{*}{ 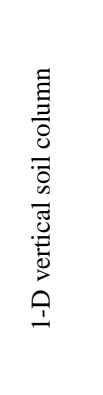 } & $1500 \mathrm{~cm}$ & 10 years & $\begin{array}{l}\text { Priestley- } \\
\text { Taylor }\end{array}$ & $\begin{array}{l}1.5 \text { and } \\
30 \mathrm{~cm}\end{array}$ & \multirow{4}{*}{ 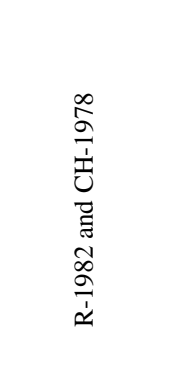 } & $1 \mathrm{~m}$ \\
\hline $\begin{array}{l}\text { G-E bucket } \\
\text { models }\end{array}$ & Daily & $\begin{array}{l}\text { Constant } \\
\text { capillary flux }\end{array}$ & & & N/A & 10 years & $\begin{array}{l}\text { Priestley- } \\
\text { Taylor }\end{array}$ & N/A & & $1 \mathrm{~m}$ \\
\hline IBIS & Hourly & $\begin{array}{l}\text { Free drainage or } \\
\text { constant soil } \\
\text { water content }\end{array}$ & & & $250 \mathrm{~cm}$ & 10 years & N/A & $2.5 \mathrm{~cm}$ & & $\begin{array}{l}\text { Variable } \\
\text { increments } \\
\text { from } 5-25 \mathrm{~cm}\end{array}$ \\
\hline Hydrus-1D & Hourly & $\begin{array}{l}\text { Free drainage or } \\
\text { constant pressure } \\
\text { head }\end{array}$ & & & $250 \mathrm{~cm}$ & 10 years & $\begin{array}{l}\text { IBIS ET }_{a} \\
\text { (saturated) }\end{array}$ & $\begin{array}{l}1.5^{*} \text { or } \\
2.5 \mathrm{~cm}\end{array}$ & & $\begin{array}{l}1 \mathrm{~m} * \text { or } \\
\text { variable } \\
\text { increments } \\
\text { from } 5-25 \mathrm{~cm}\end{array}$ \\
\hline
\end{tabular}

* The first and second terms refer to comparisons with the G-E bucket and IBIS models, respectively.

model (Eq. 18) for calculating $v$ in the soil water balance equation (Eq. 19). This version (which we refer to as "GE-bucket model-1") represents a one-way coupling, in the sense that the root zone receives a capillary flux that is independent of soil moisture fluctuations in the root zone. In the second version (referred to as "G-E-bucket model-2"), the capillary flux is directly coupled to the root-zone soil moisture in a quasi-steady-state manner. In order to accomplish this, a value for $\psi_{\mathrm{u}}$ is first obtained for each model iteration using the root-zone soil moisture from the previous time step (i.e., solving Eq. (5a) for $|h|$ ). Then, for a given $Z_{\mathrm{gw}}$, Eq. (15) is integrated numerically to solve for $v$. Finally, this calculated $v$ is added to the soil water balance in the root zone. In simulations with no groundwater (i.e., free drainage), $v$ is simply set to zero (for both G-E models). The models are run at a daily time step using the analytical method of Laio et al. (2001).

\section{Model evaluation and experimental design}

In this section, we first evaluate the models against field observations of soil moisture for a $\sim 5$-month period during the growing season of 2009 (using local meteorology and water table depth as model drivers). The field site is located at a riparian wetland in the semi-arid region of south-central
Nebraska (USA). Observed groundwater levels are introduced as the lower boundary condition for each model, and calculated soil moisture levels in the root zone are compared against those observed in the field. Later in Sect. 3.3, we describe the experimental design used to explore the sensitivity of modelled ET to soil texture, water table depth, model formulation, and node spacing. A long-term (10-year) climate dataset from a nearby meteorological station is used as the driver for these latter simulations. Groundwater levels are again introduced as the lower boundary condition, except that multiple 10-year simulations are performed across a wide range of water table depths (which are held fixed during each simulation). A summary of the models, boundary conditions, and simulation periods is presented in Table 3. Results from the model sensitivity experiments are discussed in Sect. 4.

\subsection{Field site and observational data}

A limited model-data comparison study was conducted at a riparian wetland field site in the Republican River basin of south-central Nebraska, USA (Fig. 1) to assess the viability of the models used in this study. The climate of this site is generally semi arid, with a mean annual precipitation of $430 \mathrm{~mm}$. Approximately $80 \%$ of this precipitation occurs between April and September. Irrigated croplands are 


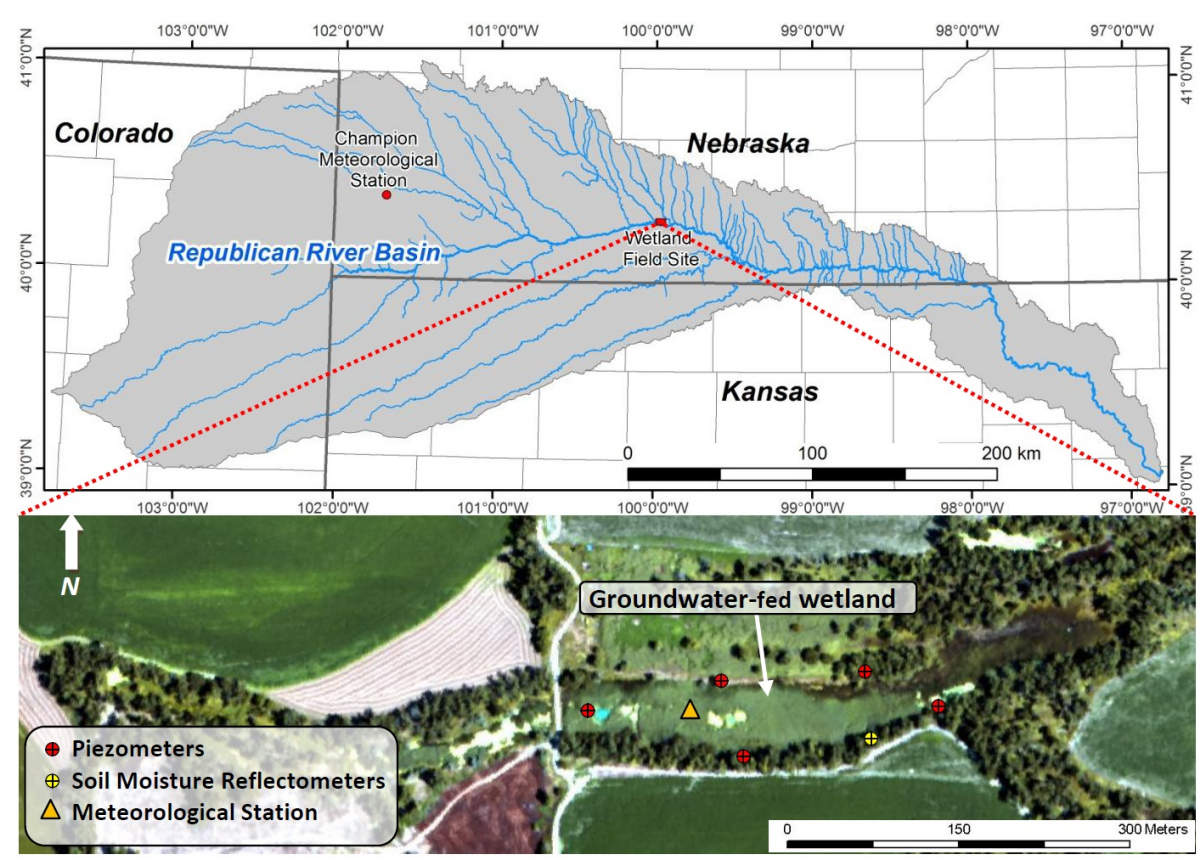

Fig. 1. Map showing the location of the piezometers, soil moisture reflectometers, and meteorological station at the wetland field site in the Republican River basin, as well as the location of the HPRCC climate station in Champion, Nebraska.

common in the region, with limited trees except in riparian zones near the Republican River and other areas where the water table is shallow. Valley wetlands with exposed water tables are generally occupied by tall grasses and open water (maximum depth $\sim 1 \mathrm{~m}$ ). The wetland field site is an oxbow channel located at $40^{\circ} 17.91^{\prime} \mathrm{N}$ and $99^{\circ} 57.90^{\prime} \mathrm{W}$, with an elevation of $664 \mathrm{~m}$ a.s.l. (above sea level) (Fig. 1). The channel is approximately $900 \mathrm{~m}$ long and $50 \mathrm{~m}$ wide, with a water depth that ranges from approximately $0-60 \mathrm{~cm}$. The wetland typically experiences groundwater discharge from spring to early summer and recharge from mid summer to early autumn (Cutrell, 2010). Both banks of the wetland channel are partially covered by old-growth cottonwood trees (Populus deltoides), while the channel itself is dominated by tall, perennial grass (primarily Phragmites australis, or common reed).

Hourly water level measurements were obtained using a series of piezometers ( $3 \mathrm{~m}$ long) and Level TROLL 300 transducers (In-Situ, Inc.). Five piezometers were deployed in the field - two in each of the southern and northern banks, and one in the wetland. Soil moisture profiles were monitored at two locations along the southern bank of the channel, where the overstory vegetation is sparse cottonwood, and the understory is short grass. The measurements were made using soil water content reflectometers (model CS616, Campbell Scientific, Inc.), positioned horizontally at approximately 10 , 20 , and $50 \mathrm{~cm}$ below the soil surface. We selected monitoring sites devoid of tree roots to avoid complications due to transpiration from the upper canopy. Meteorological measurements were also made near the middle of the wetland
(Fig. 1) to provide estimates of air temperature, relative humidity, wind speed, precipitation, and radiation (solar, longwave, and net radiation). These are used as inputs to the IBIS model, as well as for calculating $\mathrm{ET}_{\mathrm{p}}$ in the Hydrus-1D and G-E-bucket models (see Eqs. 4 and 22). Figure 2a shows the observed daily precipitation and depth-to-groundwater that were used to drive the model simulations during the 2009 evaluation period.

A previous, detailed energy balance study of the wetland site (Cutrell, 2010) found that the Priestley-Taylor method provides very good estimates of $\mathrm{ET}_{\mathrm{p}}$ during the main growing season (when water is abundant and vegetation is green). Therefore, we employ the same method here to calculate $\mathrm{ET}_{\mathrm{p}}$ as input for the Hydrus-1D and G-E-bucket models during the model evaluation portion of this study. (A different method, described in Sect. 3.3, is used to estimate $\mathrm{ET}_{\mathrm{p}}$ for the model sensitivity experiments.) We use a constant PriestleyTaylor coefficient of 1.26 (as in Cutrell, 2010), as well as the direct field measurements of net radiation to calculate $\mathrm{ET}_{\mathrm{p}}$. Ground heat flux is assumed to be $10 \%$ of net radiation, which is similar to values found in other studies (e.g., Kustas et al., 1989).

Although the understory cover of the modelled domain is grass, the solar radiation reaching the understory surface is attenuated by the sparsely distributed cottonwood trees of the upper canopy. To account for this attenuation of radiation in the Priestley-Taylor estimate of $\mathrm{ET}_{\mathrm{p}}$, we employ the method of Ritchie (1972), which uses Beer's Law to calculate attenuated net radiation $\left(R_{\mathrm{a}}\right)$ according to $R_{\mathrm{a}}=R_{\mathrm{n}} \cdot e^{-k \cdot \mathrm{LAI}}$, where $R_{\mathrm{n}}$ is measured net radiation, LAI is the leaf area index of the 

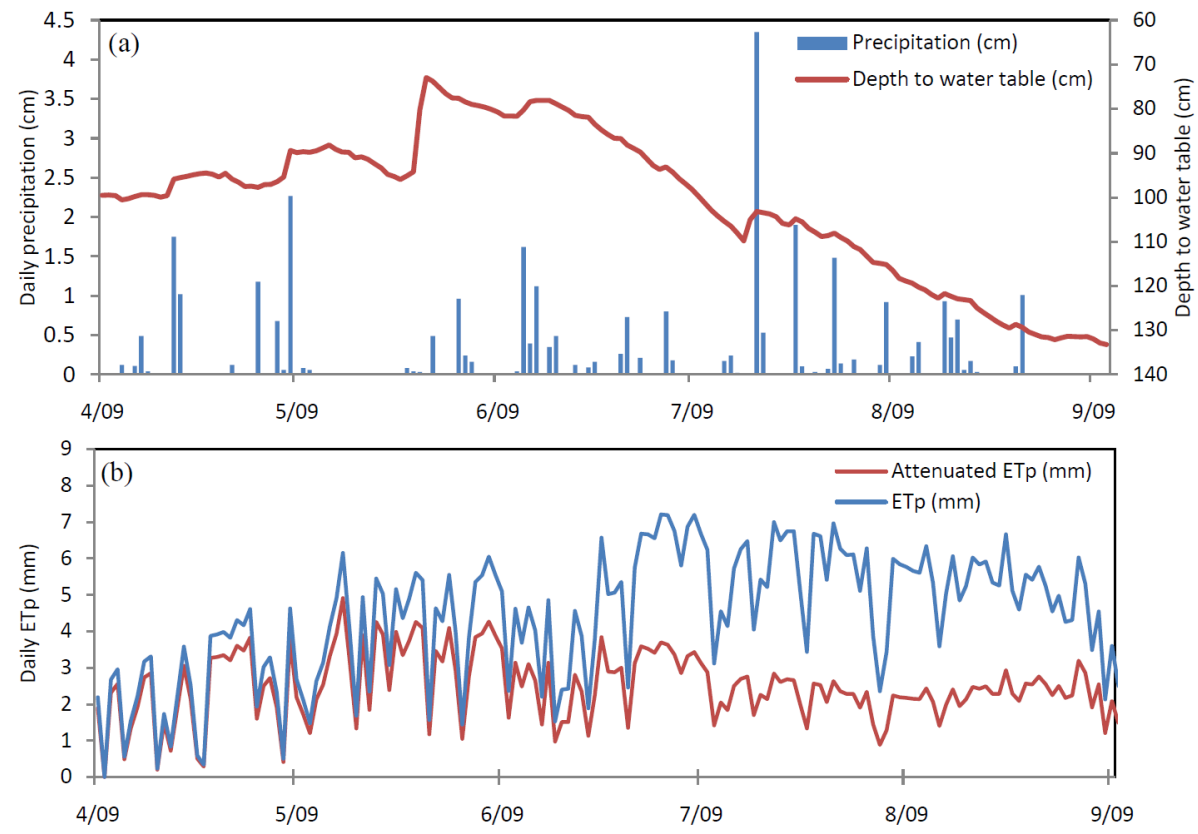

Fig. 2. (a) Observed daily precipitation and water table depth for the field site in south-central Nebraska during the 2009 growing season. (b) Daily $\mathrm{ET}_{\mathrm{p}}$ (calculated from the Priestley-Taylor equation) and "attenuated $\mathrm{ET}_{\mathrm{p}}$ " for the understory vegetation (based on LAI-reduced net radiation due to overstory vegetation).

upper canopy, and $k=0.5$ is the extinction coefficient. (For consistency, a similar attenuation was applied to the incoming solar radiation input for the IBIS model.) Upper canopy LAI is derived from MODIS imagery (MOD15A2) at a temporal resolution of 8 days, with LAI reaching a peak of $\sim 3$. Since the narrow band of cottonwood trees covers only a small area in a 1-km by 1-km MODIS pixel, we selected a larger coverage area (slightly south of the wetland) that contained the same canopy type and nearly identical cover density (as observed in the field and from areal photos). Figure $2 \mathrm{~b}$ shows the resulting $\mathrm{ET}_{\mathrm{p}}$ that was calculated from the Priestley-Taylor method using the observed and attenuated net radiation. It is evident from this figure that despite the peak in solar radiation around late June, the "attenuated $\mathrm{ET}_{\mathrm{p}}$ " reached its maximum around early May and declined thereafter (due to overstory canopy development). Thus, the impact of increased upper-canopy LAI on attenuated $\mathrm{ET}_{\mathrm{p}}$ is most significant from about mid June onward.

\subsection{Model evaluation using field observations}

Using the meteorological observations as upper boundary conditions, simulated soil moisture values from the Hydrus1D, IBIS, and G-E-bucket models were compared with volumetric water content measurements collected along the southern bank of the wetland (Fig. 3). To provide a "control" for assessing model sensitivity to groundwater, we first ran the simulations assuming free-drainage conditions (i.e., no groundwater influence). Under this condition, the
G-E-bucket models reduce to a single-bucket soil moisture model. Subsequently, we replaced the lower boundary condition of the models with the timeseries of observed water table depth that was measured along the southern bank of the wetland (Fig. 2a).

The Hydrus-1D and IBIS simulation domains are onedimensional, vertical soil columns that are $250 \mathrm{~cm}$ deep, with uniform soil characteristics and a node spacing of $2.5 \mathrm{~cm}$ (Table 3). Vegetation type is assumed to be grass in all models (specifically C3 grass in IBIS), and we use a uniform root distribution that is $50 \mathrm{~cm}$ deep (based on previously reported root depths in grasslands studies such as Jackson et al., 1996 and Wang et al., 2008). Simulated soil moisture outputs for the Hydrus-1D and IBIS models are obtained at 10,20 , and $50 \mathrm{~cm}$ below the soil surface, which is consistent with the field observations. The two G-E-bucket models provide depth-averaged volumetric water content for the entire $50-\mathrm{cm}$ root zone. To be consistent among the different models, therefore, we use only the depth-averaged, root zone soil moisture when comparing the modelled and observed volumetric water content. The soil type employed in the models is sand, using representative soil parameter values from R-1982 (Table 1). The simulations were initialized using the observed soil moisture profile, and no adjustments were made to the soil parameters to attempt to "calibrate" the models. Separate, detailed parameter optimizations - which could have improved the simulation results for the IBIS and Hydrus-1D models - were not applied, as this was not the intent of the paper. Rather, our goal is to show the models' 

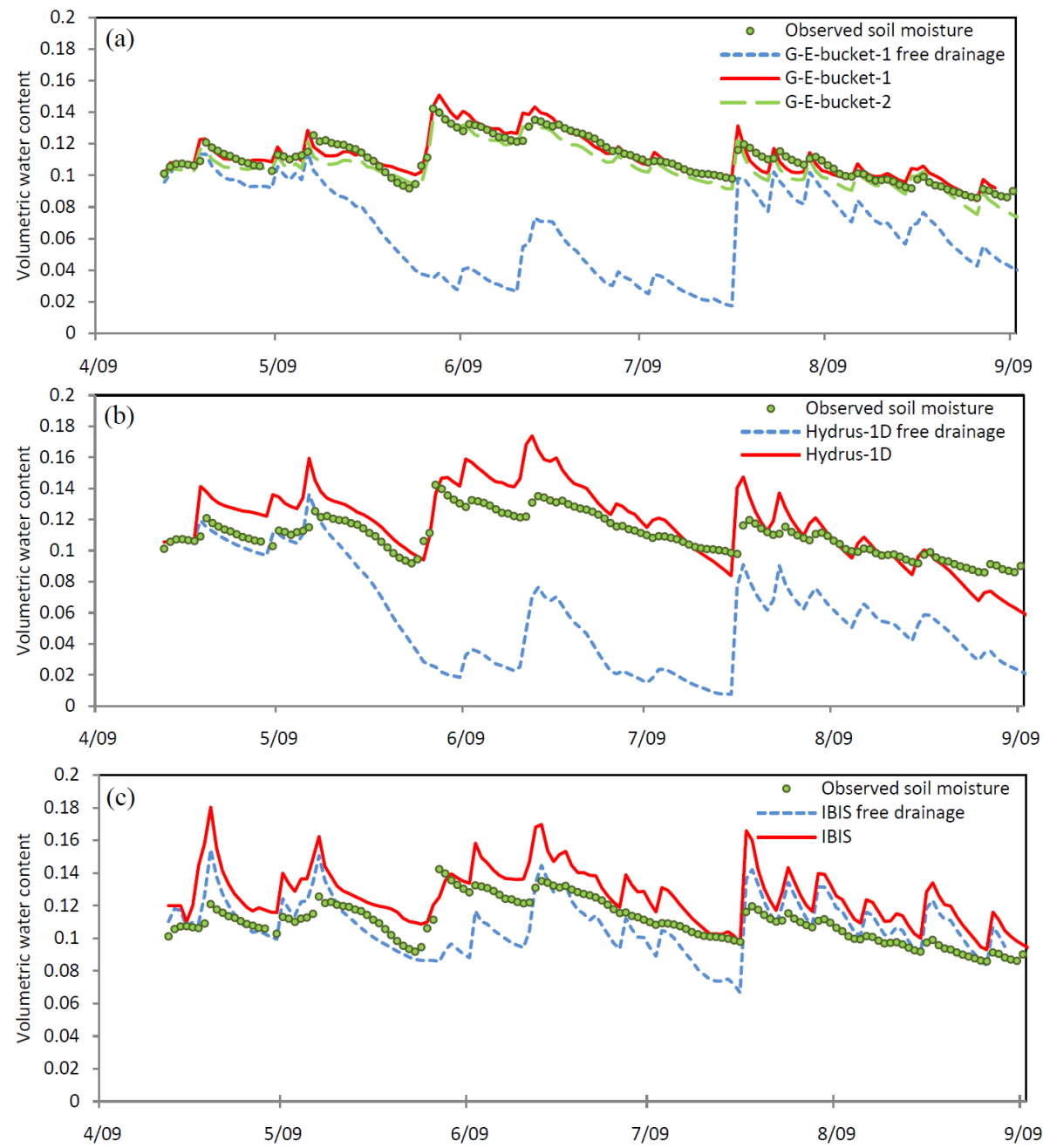

Fig. 3. Observed and simulated depth-averaged soil moisture (i.e., volumetric water content down to $50 \mathrm{~cm}$ ) for the (a) two G-E bucket models, (b) Hydrus-1D model, and (c) IBIS model during the 2009 model evaluation period (see Table 3). Simulation results using free drainage as the lower boundary condition are represented by blue dashed lines. Green dots show the daily mean soil moisture observations from the field site.

performance using standard soil moisture parameters that are based solely on soil texture (Table 1).

The results of Fig. 3 indicate that, despite the range of complexities among the models, each one showed improvements in the soil moisture simulation when groundwater was introduced as the lower boundary condition. Somewhat surprisingly, the volumetric water content predicted by the simpler G-E-bucket models showed the best agreement with the observed soil moisture timeseries. The overall influence of groundwater in the modelled soil moisture was to reduce the daily variability and increase the mean daily soil moisture, especially from early May to mid July (Fig. 3). This time period is when the water table depth was relatively shallow (roughly $75-100 \mathrm{~cm}$ below the surface; Fig. 2a). In addition, the improvement in simulated soil moisture during this highwater-table period was most dramatic for the Hydrus-1D and G-E-bucket model simulations, whereas the response in IBIS was somewhat muted. This suggests a weaker sensitivity of the IBIS model to water table variations when the depth-togroundwater is $\sim 75 \mathrm{~cm}$ or deeper (at least for sand, using R-1982 parameters). The Hydrus-1D and G-E models, on the other hand, show a greater sensitivity to the presence of groundwater, suggesting a deeper simulated "critical zone" (also discussed in Sect. 4). As ET and water table depth continued their seasonal decline beyond mid July (Fig. 2), the differences in soil moisture between the simulations with and without groundwater diminished considerably (Fig. 3). Finally, we note that the model evaluation simulations were also run using the $\mathrm{CH}-1978$ soil hydraulic parameters. These additional simulations (not shown) resulted in an increase in mean soil moisture in all models (compared to the R-1982 runs), but the general shape of the pulse-decay behaviour was not altered notably. 


\subsection{Experimental design: model sensitivity experiments}

The goal of the model sensitivity analysis is to evaluate the role of soil texture, water table depth, model formulation, and node spacing in determining mean annual ET. Although it has been suggested that the use of soil texture alone is often insufficient for estimating soil hydraulic parameters (Gutmann and Small, 2005), the availability of global soil texture maps makes it a commonly used predictor of soil hydraulic parameters for hydrologic and land surface modelling purposes. Thus, in the first set of sensitivity experiments (Table 3), we run Hydrus-1D using CH-1978 and R-1982 texture-specific, class-averaged values for four different soil textures (Table 1) under varying water table depths. Two different node spacings are used $(1.5 \mathrm{~cm}$ and $30 \mathrm{~cm})$. In the $\mathrm{sec}-$ ond set of experiments, the IBIS model and both forms of the G-E-bucket model are individually compared with Hydrus1D to investigate the role of model differences and complexities in determining the ET response to varying water table depths. Simulations using free-drainage lower boundary conditions are also compared between IBIS and Hydrus-1D.

Since the observational dataset from the wetland field site covers only one growing season (2009), measurements from a long-term meteorological station near Champion, Nebraska (a grassland site) were used to drive the model sensitivity experiments. Mean hourly and daily data were obtained from the High Plains Regional Climate Center (HPRCC) at the University of Nebraska-Lincoln for a 10-year period (19992008). The HPRCC station is located approximately $150 \mathrm{~km}$ west of the field site at $40^{\circ} 24.00^{\prime} \mathrm{N}$ and $101^{\circ} 43.20^{\prime} \mathrm{W}$ at an elevation of $1028 \mathrm{~m}$ a.s.l. Measured variables include air temperature, relative humidity, incoming solar radiation, precipitation, and wind speed. Air temperature and net radiation are used to calculate $\mathrm{ET}_{\mathrm{p}}$ via the Priestley-Taylor method (for the Hydrus-1D and G-E-bucket models). Net radiation is calculated as $63 \%$ of incoming solar radiation (based on a linear regression using data collected at the field site; $r^{2}=0.96$ ), and $10 \%$ of the net radiation is assumed to go into ground heat flux. It should be noted that IBIS is the only model used in this study that explicitly simulates snow or frozen soil processes. Precipitation and soil moisture in the Hydrus-1D and G-E-bucket models, on the other hand, are assumed to be unfrozen, regardless of the time of year. This simplification is not expected to have a significant impact on the simulated mean annual ET, since the vast majority of the land surface latent heat flux in this mid-latitude location occurs during the warm season.

The vegetation type in all four models is specified as grass (C3 grass for IBIS), with a root depth of $50 \mathrm{~cm}$ and a uniform root distribution. It is important to note that differences in root distribution have been shown to influence transpiration rates and groundwater recharge (e.g., Finch, 1998; Small, 2005; Collins and Bras, 2007). Although examining such impacts is beyond the scope of the present study, it would be interesting to include the effects of root distribution in future studies of groundwater-land surface coupling. Similarly, the sensitivity analysis presented in this paper should also be extended to other vegetation types. However, conducting this initial analysis with a shallow-rooted vegetation type is important for laying the groundwork for future studies of groundwater impacts on ET in the presence of more complex root distributions and deep-rooted water uptake.

For the first set of simulations (which involves only Hydrus-1D; Table 3), the lower boundary condition was set to a constant pressure head to represent a fixed water table depth. The depth was varied from $100 \mathrm{~cm}$ to $1400 \mathrm{~cm}$ (in increments of $100 \mathrm{~cm}$ ). 10 -year simulations were run at a daily time step for each of the two node spacings, two soil parameter datasets, four soil textures, and 14 water table depths (i.e., a total of 224 simulations). To minimize the influence of initial soil moisture conditions on the results, a "spin-up" period of 10 years or more was applied to each Hydrus-1D simulation, in which forcing data from the first year (1999) was run for multiple years until the year-end soil moisture profile no longer varied with time. The model was then run at a daily time step from 1999-2008, and mean annual ET values were calculated from this 10-year average.

In the second set of simulations, a similar experimental design was used to compare the IBIS and G-E-bucket models with Hydrus-1D (see Table 3). As before, both the CH-1978 and R-1982 soil parameter datasets were used, and 10-year simulations were performed to calculate the mean annual ET. Both of the G-E-bucket models were run at a daily time step and across the same range of water table depths described above for the Hydrus-1D simulations. The IBIS model, on the other hand, runs at an hourly time step and has a total soil depth of $250 \mathrm{~cm}$ (see Sect. 2.2). Thus, an additional set of Hydrus-1D simulations was performed (with an hourly time step, 2.5-cm node spacing, and 250-cm total soil depth), so as to be directly compatible with the IBIS results. Water table depths for the IBIS and Hydrus-1D comparison runs varied across 11 irregularly spaced intervals from $5-225 \mathrm{~cm}$ (with finer intervals near the surface), and a free-drainage simulation was also performed for each model. A 5-year spin-up period was applied to the IBIS simulations, while the G-Ebucket models were initialized by setting the soil moisture to field capacity (i.e., no spin-up period was required for the shallow, single-bucket models).

Finally, we note one additional modification to the Hydrus-1D hourly simulations that was implemented in order to provide a more direct comparison with the IBIS simulations, and this involves the calculation of $\mathrm{ET}_{\mathrm{p}}$ (and hence, $E_{a}$ ). While Hydrus-1D calculates $\mathrm{ET}_{\mathrm{a}}$ based on available water content and prescribed $\mathrm{ET}_{\mathrm{p}}$ (which we estimate from the Priestley-Taylor relationship), IBIS calculates $\mathrm{ET}_{\mathrm{a}}$ based on the sum of transpiration, intercepted evaporation, and bare soil evaporation (see Sect. 2). Therefore, to ensure the use of similar atmospheric forcing in both models (i.e., that the $\mathrm{ET}_{\mathrm{p}}$ used in Hydrus-1D is similar to what would be estimated by IBIS), we performed a set of IBIS simulations in which all 
soil layers were saturated (for all soil texture classes). The IBIS-simulated $\mathrm{ET}_{\mathrm{a}}$ from these "saturated" runs was then used as the $\mathrm{ET}_{\mathrm{p}}$ input for Hydrus-1D (see Table 3). (No such adjustment was required for the G-E/Hydrus-1D comparisons, since both models use the Priestley-Taylor method to calculate $\mathrm{ET}_{\mathrm{p}}$ ). It was found that the IBIS-estimated mean annual $\mathrm{ET}_{\mathrm{p}}$ for the 10-year period $(1052 \mathrm{~mm})$ was only $2 \%$ higher than that calculated from the Priestley-Taylor method $(1034 \mathrm{~mm})$.

\section{Results and discussion: model sensitivity experiments}

We present the results of the model sensitivity analysis in terms of the ratio of actual to potential ET (i.e. $\mathrm{ET}_{\mathrm{a}} / \mathrm{ET}_{\mathrm{p}}$ ), where both $\mathrm{ET}_{\mathrm{a}}$ and $\mathrm{ET}_{\mathrm{p}}$ represent 10-year annual mean values. This ratio represents the fraction of atmospheric evaporative demand that is actually utilized for ET. As such, $\mathrm{ET}_{\mathrm{a}} / \mathrm{ET}_{\mathrm{p}}$ characterizes the degree of water or energy limitation, with high (low) values of $\mathrm{ET}_{\mathrm{a}} / \mathrm{ET}_{\mathrm{p}}$ indicating energylimited (water-limited) conditions. $\mathrm{ET}_{\mathrm{a}} / \mathrm{ET}_{\mathrm{p}}$ can be compared to $P / \mathrm{ET}_{\mathrm{p}}$ (often referred to as the "humidity index;" Porporato et al., 2004), where $P$ is the annual mean precipitation. Although non-zero surface runoff and/or groundwater recharge would generally imply that $\mathrm{ET}_{\mathrm{a}} / \mathrm{ET}_{\mathrm{p}} \leq P / \mathrm{ET}_{\mathrm{p}}$ (in the long-term mean), capillary flux from groundwater can often lead to $\mathrm{ET}_{\mathrm{a}} / \mathrm{ET}_{\mathrm{p}} \geq P / \mathrm{ET}_{\mathrm{p}}$, particularly in dry regions. (Irrigation can also lead to $\mathrm{ET}_{\mathrm{a}}$ rates in excess of $P$, but this is not something that we examine here.) In the present study, the humidity index at the long-term HPRCC meteorological station was found to be $P / \mathrm{ET}_{\mathrm{p}}=0.41$. Thus, values of $\mathrm{ET}_{\mathrm{a}} / \mathrm{ET}_{\mathrm{p}}$ in excess of 0.41 would be indicative of a groundwater contribution to $\mathrm{ET}_{\mathrm{a}}$, with $\mathrm{ET}_{\mathrm{a}} / \mathrm{ET}_{\mathrm{p}}$ approaching 1.0 as the water table reaches the surface. As the water table depth increases, however, $\mathrm{ET}_{\mathrm{a}} / \mathrm{ET}_{\mathrm{p}}$ converges toward $P / \mathrm{ET}_{\mathrm{p}}$ in this semi-arid climate, resulting in limited runoff or groundwater recharge (Zhang et al., 2008).

\subsection{Influence of water table depth, soil parameters, and node spacing on $\mathbf{E T}_{\mathbf{a}}$}

Results of the Hydrus-1D sensitivity analysis are illustrated in Fig. 4, which shows the simulated $\mathrm{ET}_{\mathrm{a}} / \mathrm{ET}_{\mathrm{p}}$ as a function of water table depth for both large and small node spacing, two soil parameter datasets (Table 1), and four different soil texture classes. In all cases, we find that $\mathrm{ET}_{\mathrm{a}} / \mathrm{ET}_{\mathrm{p}}$ is roughly equal to 1.0 for very shallow water tables, but asymptotically approaches $P / \mathrm{ET}_{\mathrm{p}}=0.41$ as the water table depth increases. In a numerical modelling study using a fully coupled groundwater/vadose zone/land surface model, Kollet and Maxwell (2008) described the "critical zone" as the region in which a strong correlation exists between $\mathrm{ET}_{\mathrm{a}} / \mathrm{ET}_{\mathrm{p}}$ and water table depth, and they found this zone to occur at depths of $100-500 \mathrm{~cm}$ in their study area (Oklahoma, USA; generally loam and loamy sand soil textures).
The results of Fig. 4 generally agree with those of Kollet and Maxwell (2008), but clearly show that the depth and thickness of the modelled critical zones depend strongly on the soil type and (especially) the source from which the texturespecific, class-averaged values are obtained. Among the four soil textures used, silt loam shows the thickest (and deepest) critical zone, while sand shows the thinnest (Fig. 4). Clay and silty clay loam tend to exhibit the shallowest critical zone, except when using the R-1982 soil parameter dataset (in which case sand shows the shallowest critical zone).

The critical zones simulated by Hydrus-1D are significantly deeper (for all four soil types) when using the CH1978 soil parameters instead of the R-1982 parameters. In most cases, the critical zone is also thicker (especially for sand and silt loam). These results indicate that LSMs that simulate coupled water table dynamics in semi-arid regions are likely to produce more surface ET (for the same water table depth) when using $\mathrm{CH}-1978$ values for a given soil texture rather than the R-1982 values (unless the water table depth is well above or well below both critical zones). This could lead to a negative feedback, whereby the water table elevation declines until surface ET is sufficiently reduced to reach a steady-state water balance. As a result, the simulated water table depth, in the long-term mean, would be deeper in the case of the $\mathrm{CH}-1978$ values. According to Fig. 4, this difference in water table depth could be very large (e.g., greater than $\sim 5 \mathrm{~m}$ in the case of sand, or $\sim 10 \mathrm{~m}$ in the case of silt loam).

Conversely, LSMs that model capillary flux, but with fixed water table depths, are likely to simulate significantly different $\mathrm{ET}_{\mathrm{a}}$ values (and root-zone soil moisture), depending on the soil parameter dataset that is used. This difference would be particularly large when the imposed water table depth lies somewhere between the depths of the two critical zones (Fig. 4). In our own study, the $\mathrm{ET}_{\mathrm{a}}$ simulated by Hydrus-1D is up to a factor of 2.4 larger (i.e., 1.0/0.41) when CH-1978 parameters are used instead of R-1982 (e.g., for silt loam at a water table depth of $\sim 700 \mathrm{~cm}$; or sand at a water table depth of $\sim 300 \mathrm{~cm}$ ). These large differences in $\mathrm{ET}_{\mathrm{a}}$ would cause significant discrepancies in the partitioning of available energy into latent and sensible heat flux in LSMs that use fixed water table depths in semi-arid regions. As noted above (and in Fig. 4), the discrepancies become significantly minimized only if the water table depth is extremely shallow or if it drops below the deepest of the two critical zones. In the latter case, $\mathrm{ET}_{\mathrm{a}} / \mathrm{ET}_{\mathrm{p}}$ converges to a common value of $P / \mathrm{ET}_{\mathrm{p}}$ (for dry climates), regardless of the soil parameter dataset that is chosen. For wetter climates, the asymptotic value of $\mathrm{ET}_{\mathrm{a}} / \mathrm{ET}_{\mathrm{p}}$ would be less than $P / \mathrm{ET}_{\mathrm{p}}$ due to the increased partitioning of precipitation into runoff. This would also mean that the different soil parameter simulations would not necessarily converge to the same value (due to the impacts of soil physics on runoff processes). Even for the semiarid region studied here, we note that some of the asymptotic $\mathrm{ET}_{\mathrm{a}} / \mathrm{ET}_{\mathrm{p}}$ ratios are slightly lower than $P / \mathrm{ET}_{\mathrm{p}}$, showing 

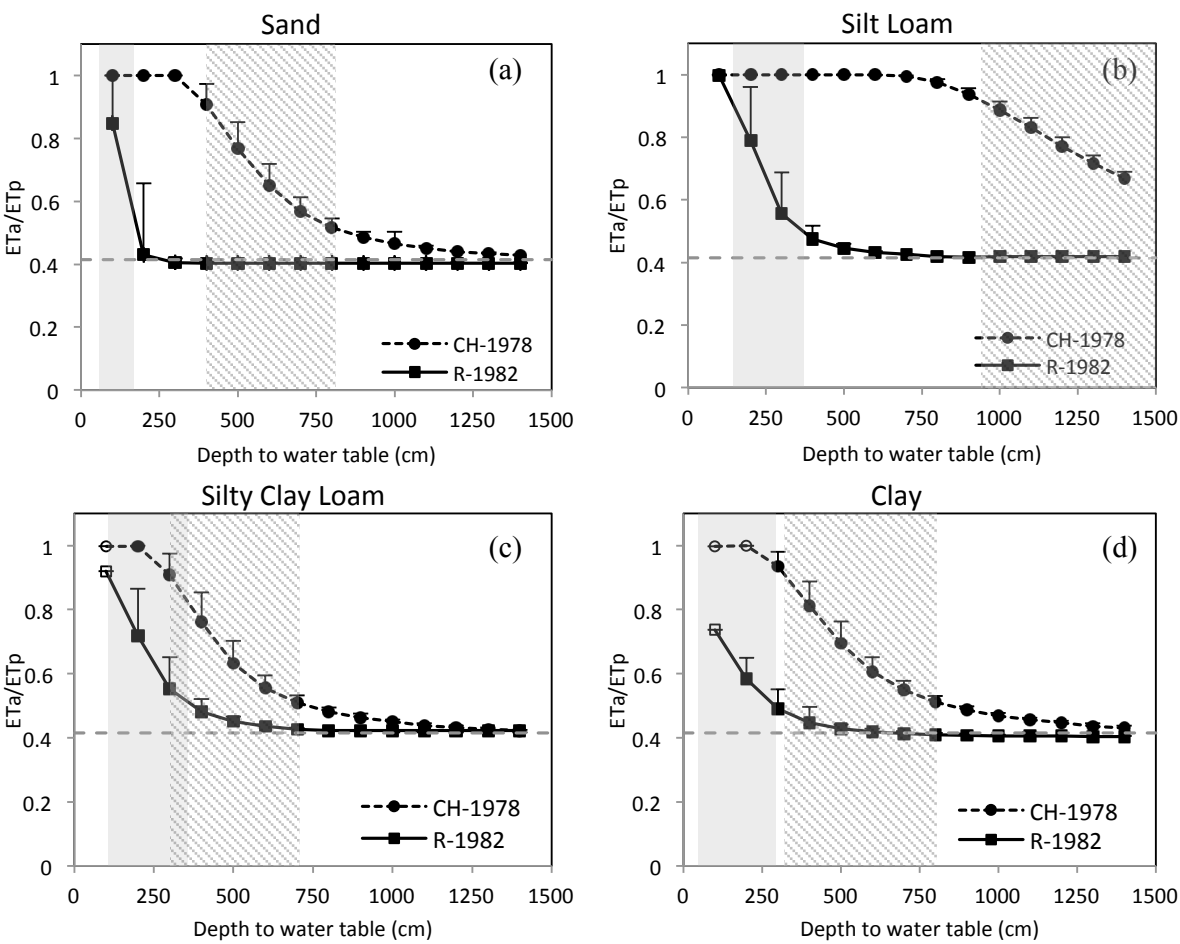

Fig. 4. Long-term mean annual $\mathrm{ET}_{\mathrm{a}} / \mathrm{ET}_{\mathrm{p}}$ versus water table depth, based on the daily Hydrus-1D 10-year simulations (see Table 3). Shown are model results for (a) sand, (b) silt loam, (c) silty clay loam, and (d) clay. Dashed and solid lines indicate model solutions using Clapp and Hornberger (1978) and Rawls et al. (1982) soil parameters, respectively (both with 1.5-cm node spacing). Vertical "error bars" represent solutions using 30-cm node spacing, while empty squares or circles indicate solutions that did not converge using a 30-cm nodal distance. The horizontal, dashed line (in grey) indicates the 10-year mean annual $P / \mathrm{ET}_{\mathrm{p}}$ ratio, where $\mathrm{ET}_{\mathrm{p}}$ is calculated from the Priestley-Taylor relationship. Gray shaded and hatched areas represent approximate critical zones for R-1982 and CH-1978 soil parameters, respectively.

subtle differences depending on soil texture (e.g., $\mathrm{ET}_{\mathrm{a}} / \mathrm{ET}_{\mathrm{p}}$ being lowest for sand). Lower values of $\mathrm{ET}_{\mathrm{a}} / \mathrm{ET}_{\mathrm{p}}$ for coarser soil texture are consistent with other modelling and water balance studies in this region (Wang et al., 2009a,b), as well as studies in other semi-arid locations (e.g. Small, 2005).

Although there are relatively few previous studies that have shown the sensitivities of surface ET to soil hydraulic properties in areas where groundwater is an important contributor to ET, various modelling studies have shown significant uncertainties in simulated groundwater recharge (Schaap and Leij, 1998; Schaap et al., 2001; Wang et al., 2009b). Faust et al. (2006) also examined the effects of chosen pedotransfer functions on the prediction of potential recharge rates and patterns, and they found that different pedotransfer functions can produce up to an orderof-magnitude variation in the total recharge simulated by a basin-scale hydrologic model. Nolan et al. (2007) pointed out that uncertainity in soil hydraulic parameters can also lead to a higher spatial variability in estimated recharge.

The effects of node spacing on the Hydrus-1D-simulated $\mathrm{ET}_{\mathrm{a}} / \mathrm{ET}_{\mathrm{p}}$ are illustrated in Fig. 4 by the vertical "error" bars (i.e., $1.5-\mathrm{cm}$ node spacing for the squares/circles vs. $30-\mathrm{cm}$ node spacing for the thin vertical lines). The results show that the use of a coarser node spacing leads to higher $\mathrm{ET}_{\mathrm{a}}$ in all cases, with the difference being largest for water table depths within the critical zone (generally $100-600 \mathrm{~cm}$ ). In some cases, the simulated $\mathrm{ET}_{\mathrm{a}} / \mathrm{ET}_{\mathrm{p}}$ for $30-\mathrm{cm}$ node spacing can be up to $60 \%$ larger than that for $1.5-\mathrm{cm}$ spacing (Fig. 4), but otherwise the differences are generally small. Associated with the higher $\mathrm{ET}_{\mathrm{a}} / \mathrm{ET}_{\mathrm{p}}$ is a slight deepening of the simulated critical zone (by $\sim 50-100 \mathrm{~cm}$ ) when using the $30-\mathrm{cm}$ node spacing. It should be noted that other investigations using the Richards equation (van Dam and Feddes, 2000) have shown that a node spacing of $\sim 5 \mathrm{~cm}$ or larger may not correctly estimate evaporation and infiltration, especially in layers close to the surface and with a shallow water table. Nevertheless, the results of the current study show that the use of two widely varying node spacings in Hydrus-1D generally leads to only moderate differences in simulated $\mathrm{ET}_{\mathrm{a}}$, except when the water table depth is within the critical zone, in which case the discrepancies can be non-trivial. Even in the latter case, however, the uncertainties due to node spacing are much less than those associated with the choice of soil hydraulic parameters (Fig. 4). 

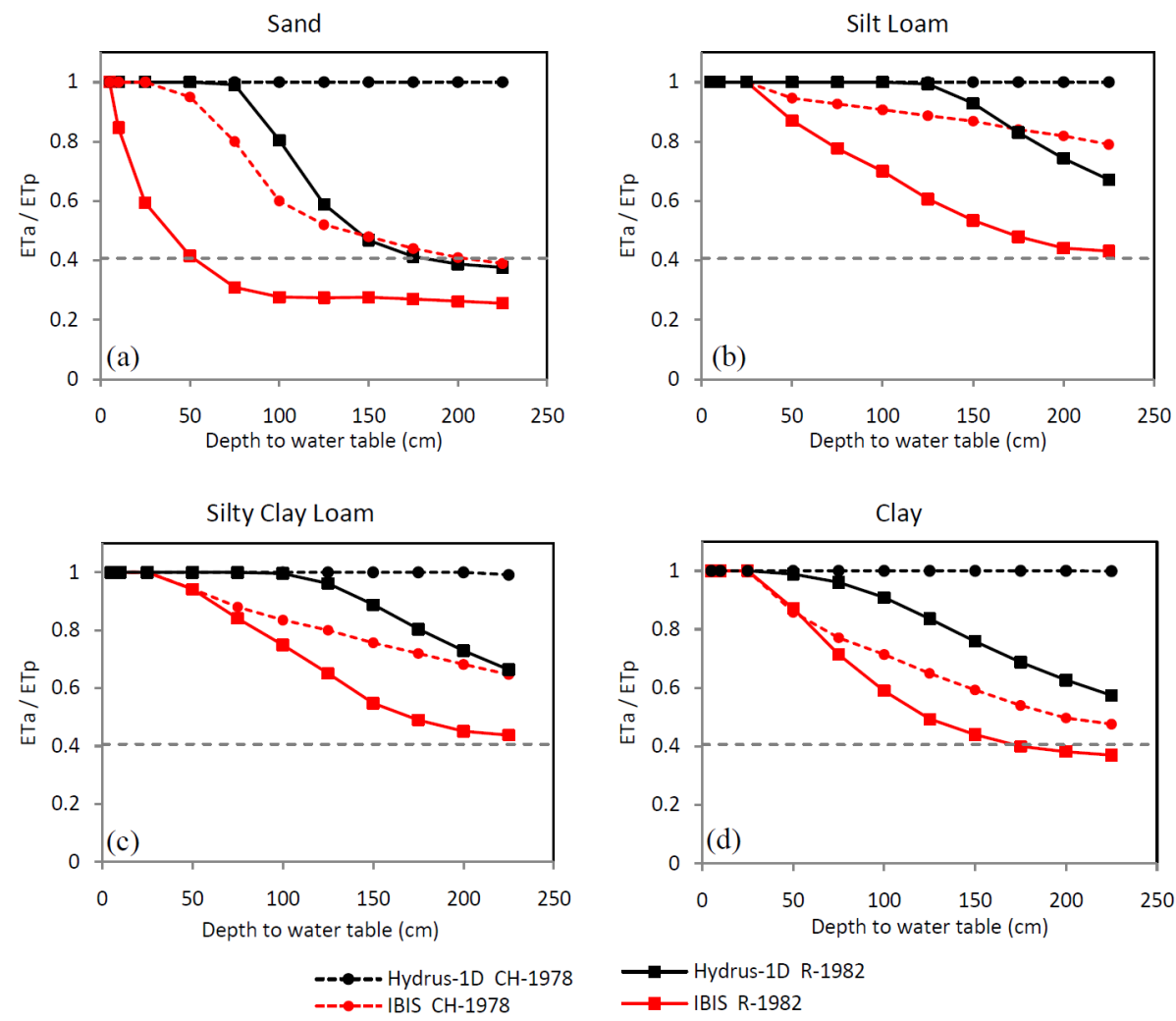

Fig. 5. Same as in Fig. 4, except for hourly Hydrus-1D (black) and IBIS (red) 10-year simulations (see Table 3). The node spacing in all simulations is $2.5 \mathrm{~cm}$, and $\mathrm{ET}_{\mathrm{p}}$ is calculated based on $\mathrm{ET}_{\mathrm{a}}$ from the "saturated" IBIS run.

\subsection{Hydrus-1D/IBIS model comparison}

To investigate the sensitivity of $\mathrm{ET}_{\mathrm{a}} / \mathrm{ET}_{\mathrm{p}}$ to differences in the numerical solution of the Richards equation (as a function of water table depth), we compare the IBIS and Hydrus1D model simulations (described in Sect. 3.3 and Table 3). As noted earlier, IBIS employs the commonly used, massconservative, $\theta$-based form of the Richards equation, while Hydrus-1D uses the mixed $\theta$ - and $h$-based form. Both model simulations use identical node spacing $(2.5 \mathrm{~cm})$, soil depth $(250 \mathrm{~cm}$ ), and atmospheric forcing (at least in terms of $P$ and IBIS-estimated $\mathrm{ET}_{\mathrm{p}}$ ). The results are shown in Fig. 5 for four soil types, 11 water table depths (ranging from 5-225 cm), and both soil parameter datasets (i.e., CH-1978 and R-1982).

In general, IBIS simulates considerably lower $\mathrm{ET}_{\mathrm{a}}$ than Hydrus-1D (by up to a factor of three), particularly for intermediate water table depths that are between the models' two simulated critical zones (Fig. 5). Only when the water table is extremely shallow $(\sim 5-25 \mathrm{~cm})$ do the models show good agreement (and not surprisingly, considering they use the same $\mathrm{ET}_{\mathrm{p}}$ ). One might also expect both models to converge to a similar value of $\mathrm{ET}_{\mathrm{a}} / \mathrm{ET}_{\mathrm{p}}$ (equal to $P / \mathrm{ET}_{\mathrm{p}}$ ) when the water table is very deep, as was found in Fig. 4 for Hydrus1D (at depths of $\sim 300-800 \mathrm{~cm}$ for R-1982 parameters, or $>1400 \mathrm{~cm}$ for $\mathrm{CH}-1978$ ). However, the shallow soil depth in
IBIS (Fig. 5) prevents us from determining the precise water table depth at which this might occur. Moreover, some of the asymptotic $\mathrm{ET}_{\mathrm{a}} / \mathrm{ET}_{\mathrm{p}}$ values for IBIS actually fall well below $P / \mathrm{ET}_{\mathrm{p}}$, particularly in the case of sand, which is coarser and allows for greater recharge (Fig. 5a). This was also found for Hydrus-1D (Fig. 4a), although the effect is more pronounced in the case of IBIS. For additional comparison, Table 4 shows results from simulations with no groundwater at all (i.e., using free-drainage lower boundary conditions and R-1982 soil parameters). Without the influence of groundwater, the $\mathrm{ET}_{\mathrm{a}} / \mathrm{ET}_{\mathrm{p}}$ values in Hydrus-1D fall somewhat below $P / \mathrm{ET}_{\mathrm{p}}=0.41$ and vary slightly by soil texture. IBIS, on the other hand, exhibits even lower values of $\mathrm{ET}_{\mathrm{a}} / \mathrm{ET}_{\mathrm{p}}$, particularly for sand $\left(\mathrm{ET}_{\mathrm{a}} / \mathrm{ET}_{\mathrm{p}}=0.248\right)$. Thus, there is a tendency for IBIS to simulate lower $\mathrm{ET}_{\mathrm{a}}$ than Hydrus-1D (and, therefore, greater surface runoff and/or recharge), with or without the influence of groundwater. (It should also be noted that this conclusion does not change if the free-drainage simulations are run with $\mathrm{CH}-1978$ parameters instead of R-1982.)

In conjunction with the lower values of $\mathrm{ET}_{\mathrm{a}}$, IBIS also simulates a shallower critical zone than Hydrus-1D (Fig. 5; also alluded to earlier in Sect. 3.2), regardless of which soil parameter dataset is used. In other words, a shallower water table is needed (in IBIS) in order to simulate the same rate of $\mathrm{ET}_{\mathrm{a}}$ as Hydrus-1D (Fig. 5). This suggests greater 

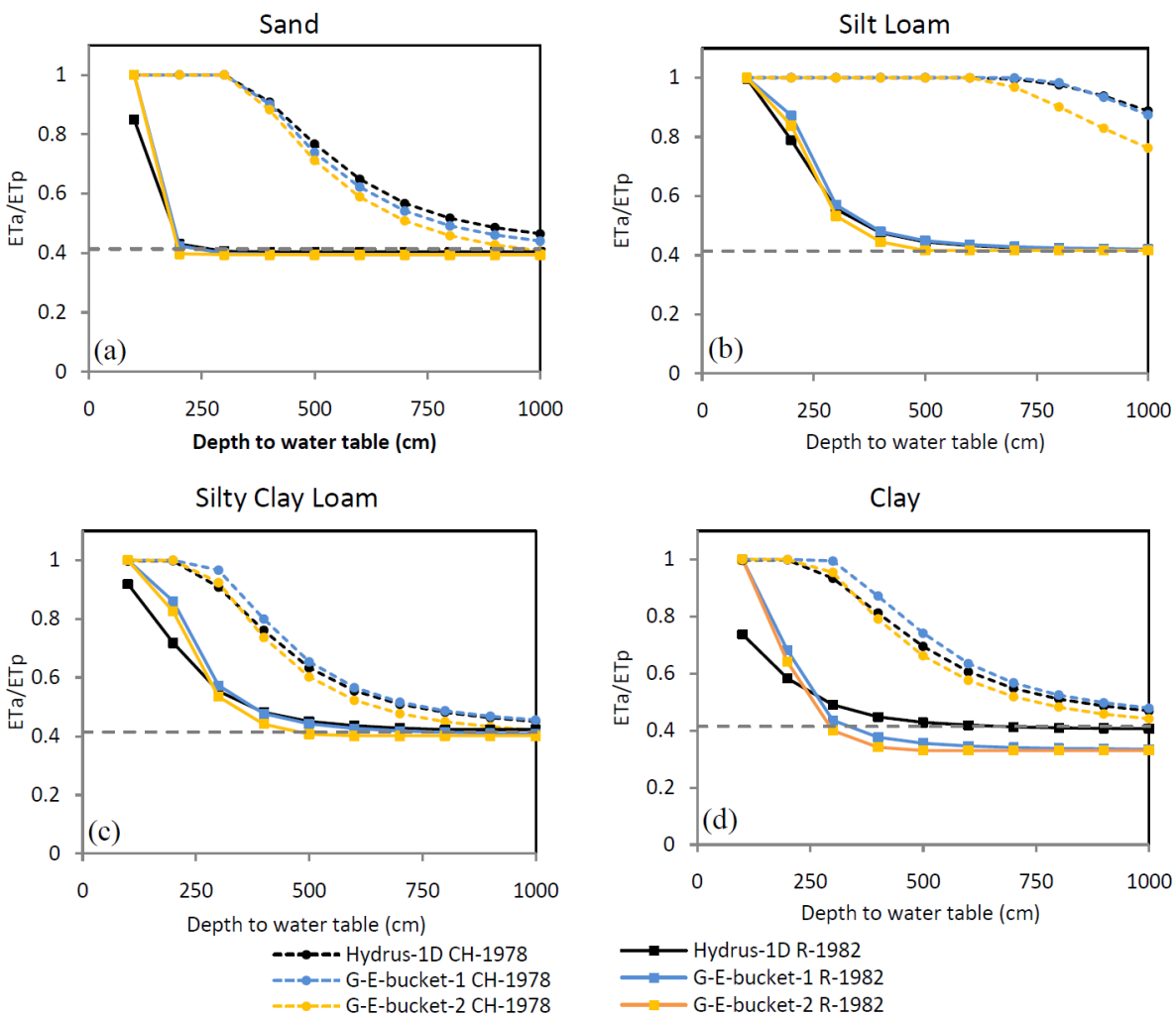

Fig. 6. Same as in Fig. 4, except for daily Hydrus-1D (black) and G-E-bucket model (1-blue, 2-yellow) 10-year simulations (see Table 3). The node spacing in the Hydrus-1D simulation is $1.5 \mathrm{~cm}$, and $\mathrm{ET}_{\mathrm{p}}$ is calculated from the Priestley-Taylor relationship.

Table 4. Long-term mean annual $\mathrm{ET}_{\mathrm{a}} / \mathrm{ET}_{\mathrm{p}}$, as simulated by IBIS and Hydrus-1D in the 10-year model sensitivity experiments (Table 3) using free-drainage lower boundary conditions. Soil hydraulic parameters from Rawls et al. (1982) are used in the simulations.

\begin{tabular}{lcc}
\hline & IBIS & Hydrus-1D \\
\hline Sand & 0.248 & 0.365 \\
Silt Loam & 0.326 & 0.396 \\
Silty Clay Loam & 0.314 & 0.389 \\
Clay & 0.305 & 0.378
\end{tabular}

capillary flux and root water uptake in Hydrus-1D, as compared to IBIS (given the same water table depth). (A higher rate of root water uptake could also explain the stronger "nogroundwater" response that was found in the Hydrus-1Dsimulated soil moisture shown earlier in Fig. 3.) Since surface ET in dry climates (or dry seasons) is often maintained through capillary rise from the water table, this is a critical issue in terms of vegetation dynamics, as well as surface energy, water, and carbon fluxes (Nepstat et al., 1994).

The difference in critical zone depths simulated by IBIS and Hydrus-1D is $\sim 100 \mathrm{~cm}$ when using the R-1982 soil parameters (Fig. 5), and considerably larger when using $\mathrm{CH}$ 1978 values (Figs. 4 and 5). These model-related differences are comparable to the "uncertainty" in IBIS-simulated critical zone depth that is associated with using different soil parameter datasets (Fig. 5). In contrast, Hydrus-1D exhibits a much greater sensitivity to the choice of soil hydraulic parameters (Fig. 4), showing differences in critical zone depth of over $1000 \mathrm{~cm}$ between R-1982 and CH-1978. These results indicate that resolving issues related to proper soil parameterizations is extremely important and, in some cases, more important than even the choice of which model to use. In terms of critical zone depth, however, IBIS shows considerably less sensitivity to the choice of soil hydraulic parameters than Hydrus-1D.

\subsection{Hydrus-1D/G-E-bucket model comparison}

In Fig. 6, we examine the sensitivity of simulated $\mathrm{ET}_{\mathrm{a}} / \mathrm{ET}_{\mathrm{p}}$ to three model formulations: (1) G-E-bucket model-1, (2) G-Ebucket model-2, and (3) Hydrus-1D. Identical soil parameter values and climate forcing are used in both models (Table 3 ), and the water table depths vary from $100-1000 \mathrm{~cm}$ (in increments of $100 \mathrm{~cm}$ ). In general, the models agree well with each other, especially for sand and silty clay loam. The simulated critical zones are similar for the two models (in terms 
of both depth and thickness), except in the case of clay (with R-1982 soil parameters). The latter scenario shows a thicker critical zone in the Hydrus-1D model $(\sim 500 \mathrm{~cm})$ as compared to both of the G-E-bucket models $(\sim 250 \mathrm{~cm})$. Another model-related difference that is evident in the clay/R-1982 scenario (Fig. 6d) is the simulation of lower $\mathrm{ET}_{\mathrm{a}} / \mathrm{ET}_{\mathrm{p}}$ values by Hydrus-1D (as compared to both of the G-E-bucket models) when the water table is shallow $(<200 \mathrm{~cm})$. This pattern reverses for deeper water tables $(>300 \mathrm{~cm})$, where Hydrus-1D instead converges to a higher $\mathrm{ET}_{\mathrm{a}} / \mathrm{ET}_{\mathrm{p}}$ value than that of the G-E models. The asymptotic value of $\mathrm{ET}_{\mathrm{a}} / \mathrm{ET}_{\mathrm{p}}$ in Hydrus-1D (for clay) is almost identical to $P / \mathrm{ET}_{\mathrm{p}}$, whereas the G-E-model converges to a notably lower value (implying non-zero recharge and/or surface runoff, similar to what was found for IBIS in Fig. 5 and Table 4).

As was shown earlier for Hydrus-1D, the $\mathrm{ET}_{\mathrm{a}} / \mathrm{ET}_{\mathrm{p}}$ ratios simulated by both of the G-E-bucket models are very sensitive to the choice of soil hydraulic parameters (R-1982 and $\mathrm{CH}-1978)$. In fact, the soil parameter-related differences shown in Fig. 6 are much larger than the differences in $\mathrm{ET}_{\mathrm{a}} / \mathrm{ET}_{\mathrm{p}}$ among the three model simulations. Given the wide range in complexity among all four models examined in this study, this again highlights the importance of using proper soil hydraulic parameters in modelling the response of surface ET to fluctuations in water table depth (particularly near the critical zone). The results of Fig. 6 also suggest that simpler models that are more computationally efficient (such as the G-E-bucket model) can be effectively used to simulate groundwater impacts on $\mathrm{ET}_{\mathrm{a}}$, so long as the soil hydraulic parameters are properly specified.

\section{Summary and conclusions}

Soil moisture in the root zone is a critical mediator of land surface-atmosphere interactions and vegetation dynamics. In regions with shallow groundwater, capillary rise from the water table can be a significant source of moisture to the root zone. In this study, we examined the role of different numerical model parameterizations in quantifying the impact of groundwater on root zone soil moisture and ET, as well as model sensitivity to soil texture and water table depth. The four models used in this study are: (1) the Hydrus1D model (Simunek et al., 2005), (2) the Integrated Biosphere Simulator (IBIS; Foley et al., 1996; Kucharik et al., 2000), and (3-4) two variants of the Gardner-Eagleson (GE) model that are coupled with a bucket-type soil moisture model using successive steady-state flux conditions. The GE model offers an analytical solution to calculate a constant rate of capillary flux from the water table to the unsaturated zone under steady-state soil moisture conditions. Model values for soil hydraulic parameters were obtained from two soil texture-based lookup tables that are commonly used by LSMs (Table 1), namely the parameter sets of Clapp and Hornberger (1978) and Rawls et al. (1982).
The models were first evaluated using observations from a semi-arid field site in a region with shallow groundwater (located in south-central Nebraska, USA). Root-zone soil moisture and water table fluctuations were measured at the field site for a $\sim 5$-month period during the 2009 growing season. All models compared well with observations when using water table depth as a lower boundary condition and soil hydraulic parameters from Rawls et al. (1982). The simulations worsened considerably under free-drainage boundary conditions (i.e., no groundwater influence). Soil moisture was more accurately simulated in the two G-E models than both Hydrus-1D and IBIS, while IBIS showed the lowest sensitivity to the presence/absence of groundwater. Use of the Clapp and Hornberger (1978) parameter dataset led to significant overestimates of mean soil moisture in all models (but with little change in simulated variability). Sensitivity analysis of the models to water table depth, soil texture, node spacing, and soil parameters revealed several key findings that are summarized below.

Model simulations showed that the depth and thickness of the critical zone, which is the zone of strongest influence of water table on surface ET, is (in most cases) significantly affected by soil texture. The simulated critical zone for silt loam, for example, was found to be much deeper and thicker than that for sand (regardless of model choice or soil parameter dataset). On the other hand, the impact of soil hydraulic parameters on surface ET was generally found to be much larger than that of soil texture. Clapp and Hornberger (1978) soil parameters consistently produced much deeper critical zones than those obtained using the Rawls et al. (1982) parameters. Significant differences in actual evapotranspiration $\left(E T_{a}\right)$ were also found (up to a factor of 2.4) as a result of using different soil parameters, particularly when water table depths were located between the two simulated critical zones. Such differences could introduce a significant bias in the partitioning of available energy into latent and sensible heat fluxes in LSMs, as well as errors in predicting water table position in coupled (two-way) land surface-groundwater models. For very deep water tables or free-drainage conditions (i.e., no influence from groundwater at all), the difference in simulated $\mathrm{ET}_{\mathrm{a}}$ between the two soil parameter datasets became much smaller, but not necessarily negligible. Only for extremely shallow water tables did the models converge to identical values of $\mathrm{ET}_{\mathrm{a}}$ (equal to $\mathrm{ET}_{\mathrm{p}}$ ). The use of a much larger node spacing in Hydrus-1D (30-cm instead of $1.5-\mathrm{cm}$ ) led to a slightly deeper critical zone (by $\sim 50$ $100 \mathrm{~cm}$ ) and higher simulated $\mathrm{ET}_{\mathrm{a}}$ rates (particularly when the water table depth was within a range of $\sim 100-600 \mathrm{~cm}$ ). In general, however, the effects of node spacing were found to be significantly less than those related to soil hydraulic parameters.

The Hydrus-1D and IBIS models were used to examine the implications of using different forms of the Richards equation. IBIS uses the $\theta$-based form, while Hydrus-1D solves the mixed $\theta$ - and $h$-based form. The two models 
were found to be in good agreement with each other only in cases of very shallow water table $(5-25 \mathrm{~cm}$, depending on soil texture). Moderate agreement was also evident under free-drainage conditions, with IBIS simulating 18-32\% lower $\mathrm{ET}_{\mathrm{a}}$ than Hydrus-1D (and, therefore, greater recharge). When the water table was near the critical zone, however, there was a much greater difference between the $\mathrm{ET}_{\mathrm{a}}$ values predicted by the two models. Regardless of the soil parameters and texture type, Hydrus-1D consistently predicted a higher $\mathrm{ET}_{\mathrm{a}} / \mathrm{ET}_{\mathrm{p}}$ ratio than IBIS. Especially for sand and clay, the difference was as high as a factor of two to three. This difference would have a major impact on regional energy and water balance predictions. We attribute the disagreement between the two models largely to differences in the form of the Richards equation, since both models used similar forcing, node spacing, and soil parameters. On the other hand, the models' different formulations for calculating $\mathrm{ET}_{\mathrm{a}}$ could also be leading to some of the discrepancies (despite the use of identical $\mathrm{ET}_{\mathrm{p}}$ ). Finally, we note that IBIS was found to have a lower sensitivity to soil hydraulic parameters than Hydrus-1D. The parameter-related differences in IBIS-simulated $\mathrm{ET}_{\mathrm{a}} / \mathrm{ET}_{\mathrm{p}}$, however, were by no means negligible (and, in fact, were comparable to the inter-model differences).

The two variants of the G-E-bucket model were also compared to Hydrus-1D and, overall, were found to be in slightly better agreement with Hydrus-1D than IBIS. The models showed good agreement with Hydrus-1D in predicting $\mathrm{ET}_{\mathrm{a}} / \mathrm{ET}_{\mathrm{p}}$ for most soil textures (especially sand and silty clay loam), although some discrepancies were found when soil parameters from Rawls et al. (1982) were used. In the case of clay, for example, the two G-E-bucket models converged to a lower value of $\mathrm{ET}_{\mathrm{a}} / \mathrm{ET}_{\mathrm{p}}$ (at deep water table depths) than was simulated by Hydrus-1D (implying greater recharge in the G-E models, as was also found for IBIS). At water table depths less than $\sim 200 \mathrm{~cm}$, however, the GE-bucket models simulated higher values of $\mathrm{ET}_{\mathrm{a}} / \mathrm{ET}_{\mathrm{p}}$ (for clay) than Hydrus-1D. Overall, the three-model comparison clearly showed that simulations of surface ET (in the presence of groundwater) are much more sensitive to the choice of soil hydraulic parameters than to the choice of model formulation. As noted above, even IBIS showed a sensitivity to soil hydraulic parameters that was comparable to the inter-model differences in $\mathrm{ET}_{\mathrm{a}} / \mathrm{ET}_{\mathrm{p}}$. Thus, we conclude that resolving issues related to the parameterization of soil hydraulic properties is of utmost importance, as these parameters were found to play a larger role than other factors such as node spacing, soil texture, or even the choice of model.

It has been previously shown that neglecting the role of groundwater in LSMs may result in significant errors in the surface energy and water balance, especially in areas where the water table is shallow (e.g., Kollet and Maxwell, 2008; Maxwell and Kollet, 2008). We show in this new study that even coupled models may lead to inaccurate results, depending on the choice of soil parameters and solution methods that are used for simulating the interaction between saturated and unsaturated zones. Hence, further studies are needed that integrate field measurements with modelling to better understand and predict the coupling of groundwater with the land surface and overlying atmosphere. Our own study has examined model- and soil parameter-related sensitivities using validation and forcing data from a semi-arid, grassland location. It would be valuable to extend this study to other regions with different climate, land cover, and soil types to assess the universality of the current findings. In particular, field studies which explicitly measure $\mathrm{ET}_{\mathrm{a}}$ as a function of water table depth and soil parameters (e.g., using eddy covariance, energy balance, or lysimeter techniques) would be especially useful for testing and validating coupled groundwater-land surface hydrologic models.

Acknowledgements. The authors would like to thank G. Cutrell, K. Herrman, S. Walters, and D. Scott for their assistance with the fieldwork, as well as the High Plains Regional Climate Center (HPRCC) for supplying some of the meteorological data. We appreciate the input of G. de Rooij, T. Ferre, and two anonymous reviewers, whose constructive comments helped to improve the manuscript significantly. This research was supported through funding from the Nebraska Environmental Trust (NET), the University of Nebraska Water Resources Advisory Panel (WRAP), the University of Nebraska Rural Initiative, and the US Department of Energy's Office of Science through the Midwestern Regional Center of the National Institute for Climatic Change Research at the Michigan Technological University, under Award Number DE-FC02-06ER64158.

Edited by: G. H. de Rooij

\section{References}

Allen, M. B. and Murphy, C. L.: A Finite-Element Collocation Method for Variably Saturated Flow in Two Space Dimensions, Water Resour. Res., 22, 1537-1542, doi:10.1029/WR022i011p01537, 1986.

Anat, A., Duke, H. R., and Corey, A. T.: Steady upward flow from water table, Hydrol. Pap. 7, Colo. State Univ., Fort Collins, 1965.

Bogaart, P. W., Teuling, A. J., and Troch, P. A.: A state-dependent parameterization of saturated-unsaturated zone interaction, Water Resour. Res., 44, W11423, doi:10.1029/2007WR006487, 2008.

Brolsma, R. J. and Bierkens, M. F. P.: Groundwater - soil water - vegetation dynamics in a temperate forest ecosystem along a slope, Water Resour. Res., 43, W01414, doi:10.1029/2005WR004696, 2007.

Brooks, R. H. and Corey, A. T.: Properties of porous media affecting fluid flow, J. Irrig. Drain. Div. Am. Soc. Civ. Eng., 92(IR2), 61-88, 1966.

Campbell, G. S.: A simple method for determining unsaturated conductivity from moisture retention data, Soil Sci., 117, 311-314, 1974.

Celia, M. A., Bouloutas, E. T., and Zarba R. L.: A general massconservative numerical solution for the unsaturated flow equation, Water Resour. Res., 26, 1483-1496, 1990. 
Chen, X. and $\mathrm{Hu}, \mathrm{Q} .:$ Groundwater influences on soil moisture and surface evaporation, J. Hydrol., 297, 285-300, doi:10.1016/j.jhydrol.2004.04.019, 2004.

Clapp, R. B. and Hornberger, G., M.: Empirical equations for some soil hydraulic properties, Water Resour. Res., 14, 601-604, 1978.

Collins, D. B. G. and Bras, R. L.: Plant rooting strategies in water-limited ecosystems, Water Resour. Res., 43, W06407, doi:10.1029/2006WR005541, 2007.

Cutrell, G. J.: Seasonal energy and water balance of a Phragmites Australis-dominated wetland in the Republican River basin (southwestern Nebraska, USA), Master's Thesis, University of Nebraska, Lincoln, 128 pp., 2010.

De Rooij, G. H.: Comments on "Improving the Numerical Simulation of Soil Moisture-Based Richards Equation for Land Models with a Deep or Shallow Water Table", J. Hydrometeorol., 11, 1044-1050, doi:10.1175/2010JHM1189.1, 2010.

Dickinson, R. E., Henderson-Sellers, A., and Kennedy, P. J.: Biosphere-Atmosphere Transfer Scheme (BATS) version 1e as coupled to the NCAR Community Climate Model, Tech. Note NCAR/TN-387+STR, Nat. Cent. for Atmos. Res., Boulder, Colorado, 1993.

Eagleson, P.: Climate, soil, and vegetation: 3. A simplified model of soil moisture movement in the liquid phase, Water Resour. Res., 14, 722-730, 1978.

Famiglietti, J. S. and Wood, E. F.: Multiscale modelling of spatially variable water and energy balance processes, Water Resour. Res., 30, 3061-3078, 1994.

Fan, Y., Miguez-Macho, G., Weaver, C. P., Walko, R., and Robock, A.: Incorporating water table dynamics in climate modeling: 1. Water table observations and equilibrium water table simulations, J. Geophys. Res., 112, D10125, doi:10.1029/2006JD008111, 2007.

Faust, A. E., Ferré, T. P. A., Schaap, M. G., and Hinnell, A. C.: Can basin-scale recharge be estimated reasonably with water balance models?, Vadose Zone J., 5, 850-855, doi:10.2136/vzj2005.0109, 2006.

Feddes, R. A., Kowalik, P. J., and Zarandy, H.: Simulation of field water use and crop yield, in: Simulation Monographs, Pudoc, Wageningen, 188 pp., 1978.

Ferguson, I. M. and Maxwell, R. M.: Role of groundwater in watershed response and land surface feedbacks under climate change, Water Resour. Res., 46, W00F02, doi:10.1029/2009WR008616, 2010.

Finch, J. W.: Estimating direct groundwater recharge using a simple water balance model - sensitivity to land surface parameters, J. Hydrol., 211(14), 112-125, 1998.

Foley, J. A., Prentice, I. C., Ramankutty, N., Levis, S., Pollard, D., Sitch, S., and Haxeltine A.: An integrated biosphere model of land surface processes, terrestrial carbon balance, and vegetation dynamics, Global Biogeochem. Cyc., 10, 603-628, 1996.

Gardner, W. R.: Some steady state solutions of the unsaturated moisture flow equation with application to evaporation from a water table, Soil Sci., 85, 244-249, 1958.

Gutmann, E. and Small, E.: The effect of soil hydraulic properties vs. soil texture in land surface models, Geophys. Res. Lett., 32, L02402, doi:10.1029/2004GL021843, 2005.

Hills, R. G., Porro, I., Hudson, D. B., and Wierenga, P. J.: Modeling one-dimensional infiltration into very dry soils 1 . Model development and evaluation, Water Resour. Res., 25, 1259-1269,
doi:10.1029/WR025i006p01259, 1989.

Jackson, R. B., Canadell, J., Ehleringer, J. R., Mooney, H. A., Sala, O. E., and Schulze, E. D.: A global analysis of root distributions for terrestrial biomes, Oecologia, 108, 389-411, 1996.

Kim, Y. and Eltahir, E. A. B.: Role of topography in facilitating coexistence of trees and grasses within savannas, Water Resour. Res., 40, W07505, doi:10.1029/2003WR002578, 2004.

Kirkland, M. R., Hills, R. G., and Wierenga, P. J.: Algorithms for solving Richards' equation for variably saturated soils, Water Resour. Res., 28, 2049-2058, doi:10.1029/92WR00802, 1992.

Kollet, S. J. and Maxwell, R. M.: Capturing the influence of groundwater dynamics on land surface processes using an integrated, distributed watershed model, Water Resour. Res., 44, W02402, doi:10.1029/2007WR006004, 2008.

Kucharik, C. J., Foley, J. A., Delire, C., Fisher, V. A., Coe, M. T., Lenters, J. D., Young-Molling, C., and Ramankutty, N.: Testing the performance of a dynamic global ecosystem model: Water balance, carbon balance, and vegetation structure, Global Biogeochem. Cyc., 14, 795-825, 2000.

Kustas, W. P., Choudhury, B. J., Moran, M. S., Reginato, R. J., Jackson, R. D., Gay, L. W., and Weaver, H. L.: Determination of sensible heat ?ux over sparse canopy using thermal infrared data, Agr. Forest Meteorol., 44, 197-216, 1989.

Laio, F., Porporato, A., Ridolfi, L., and Rodriguez-Iturbe, I.: Plants in water controlled ecosystems: active role in hydrologic processes and response to water stress II. Probabilistic soil moisture dynamics, Adv. Water Resour., 24, 707-723, 2001.

Laio, F., Tamea, S., Ridolfi, L., D’Odorico, P., and RodriguezIturbe, I.: Ecohydrology of groundwater-dependent ecosystems: 1. Stochastic water table dynamics, Water Resour. Res., 45, W05419, doi:10.1029/2008WR007292, 2009.

Lenters, J., Coe, M. T., and Foley, J. A.: Surface water balance of the continental United States, 1963-1995: Regional evaluation of a terrestrial biosphere model and the NCEP/NCAR reanalysis, J. Geophys. Res., 105, 22393-22425, 2000.

Li, K. Y., Coe, M. T., and Ramankutty, N.: Investigation of hydrological variability in West Africa using land surface models, J. Climate, 18, 3173-3188, doi:10.1175/JCLI3452.1, 2005.

Liang, X., Xie, Z., and Huang, M.: A new parameterization for surface and groundwater interactions and its impact on water budgets with the variable infiltration capacity (VIC) land surface model, J. Geophys. Res., 108(D16), 8613, doi:10.1029/2002JD003090, 2003.

Mausbach, M. J.: Soil survey interpretations for wet soils, in: Preceedings of the 8th International Soil Correlation Meeting (VIII ISCOM): Characterization, classification and utilization on wet soils, edited by: Kimble, J. M., USDA Soil Conservation Service, National Soil Survey Center, Lincoln, NE, 172-178, 1992.

Maxwell, R. M. and Kollet, S. J.: Interdependence of groundwater dynamics and land-energy feedbacks under climate change, Nat. Geosci., 1(10), 665-669, doi:10.1038/ngeo315, 2008.

Maxwell, R. M. and Miller, N. L.: Development of a coupled land surface and groundwater model, J. Hydrometeorol., 6, 233-247, 2005.

Maxwell, R. M., Chow, F. K., and Kollet, S. J.: The groundwater-land-surface-atmosphere connection: Soil moisture effects on the atmospheric boundary layer in fullycoupled simulations, Adv. Water Resour., 30, 2447-2466, 
doi:10.1016/j.advwatres.2007.05.018, 2007.

Nepstad, D. C., de Carvalho, C. R., Davidson, E. A., Jipp, P. H., Lefebvre, P. A., Negrelros, G. H., da Silva, E. D., Stone, T. A., Trumbore, S. E., and Vieira, S.: The role of deep roots in the hydrological and carbon cycles of Amazonian forests and pastures, Nature, 372, 666-669, 1994.

Neuman, S. P., Feddes, R. A., and Bresler, E.: Finite element simulation of flow in saturated - unsaturated soils considering water uptake by plants, Third Annual Report, Project No. A10- SWC77, Hydraulic Engineering Lab., Technion, Haifa, Israel, 1974.

Niu, G.-Y., Yang, Z.-L., Dickinson, R. E., Gulden, L. E., and $\mathrm{Su}, \mathrm{H}$.: Development of a simple groundwater model for use in climate models and evaluation with Gravity Recovery and Climate Experiment data, J. Geophys. Res., 112, D07103, doi:10.1029/2006JD007522, 2007.

Nolan, B. T., Healy, R. W., Taber, P. E., Perkins, K., Hitt, K. J., and Wolock, D. M.: Factors influencing ground-water recharge in the eastern United States, J. Hydrol., 332, 187-205, doi:10.1016/j.jhydrol.2006.06.029, 2007.

Pan, L. and Wierenga, P. J.: A transformed pressure headbased approach to solve Richards' equation for variably saturated soils, Water Resour. Res., 31, 925-931, 1995.

Pollard, D. and Thompson, S. L.: Use of a land-surface transfer scheme (LSX) in a global climate model: The response to doubling stomatal resistance, Global Planet. Change, 10, 129-161, 1995.

Porporato, A., Daly, E., and Rodriguez-Iturbe, I.: Soil water balance and ecosystem response to climate change, Am. Nat., 164, 625632, 2004.

Priestley, C. H. B. and Taylor, R. J.: On the assessment of surface heat flux and evaporation using large scale parameters, Mon. Weather Rev., 100, 81-92, 1972.

Rawls, W. J., Brakensiek, D. L., and Saxton, K. E.: Estimation of soil water properties, T. ASAE, 25, 1316-1320 and 1328, 1982.

Ridolfi, L., D'Odorico, P., Laio, F., Tamea, S., and RodriguezIturbe, I.: Coupled stochastic dynamics of water table and soil moisture in bare soil conditions, Water Resour. Res., 44, W01435, doi:10.1029/2007WR006707, 2008.

Ripple, C. D., Rubin, J., and van Hylckama, T. E. A.: Estimating steady state evaporation rates from bare soils under conditions of high water table, US Geological Survey Water-Supply Paper, 2019A, 1972.

Ritchie, J. T.: Model for predicting evaporation from a row crop with incomplete cover, Water Resour. Res., 8, 1204-1213, doi:10.1029/WR008i005p01204, 1972.

Salvucci, G. D.: An approximate solution for steady vertical flux of moisture through an unsaturated homogeneous soil, Water Resour. Res., 29, 3749-3753, 1993.

Scanlon, B. R., Christman, M., Reedy, R. C., Porro, I., Simunek, J., and Flerchinger, G. N.: Intercode comparisons for simulating water balance of surficial sediments in semiarid regions, Water Resour. Res., 38, 1323, doi:10.1029/2001WR001233, 2002.

Schaap, M. G. and Leij, F. J.: Database-related accuracy and uncertainty of pedotransfer functions, Soil Sci., 163, 765-779, doi:10.1097/00010694-199810000-00001, 1998.

Schaap, M. G., Leij, F. J., and van Genuchten, M. T.: ROSETTA: A computer program for estimating soil hydraulic parameters with hierarchical pedotransfer functions, J. Hydrol., 251, 163-176, doi:10.1016/S0022-1694(01)00466-8, 2001.
Scott, R. L., Shuttleworth, W. J., Keefer, T. O., and Warrick, A. W.: Modeling multiyear observations of soil moisture recharge in the semiarid American Southwest, Water Resour. Res., 36, 2233 2247, 2000.

Sellers, P. J., Randall, D. A., Collatz, J. A., Berry, J., Field, C., Dazlich, D. A., and Zhang, C.: A revised land-surface parameterization (SiB2) for atmospheric GCMs, 1, Model Formulation, J. Climate, 9, 676-705, 1996.

Simunek, J., van Genuchten, M. T., and Sejna M.: The HYDRUS1D software package for simulating the one-dimensional movement of water, heat, and multiple solutes in variably saturated media, version 3.0, HYDRUS Software Ser. 1, Dep. of Environ. Sci., Univ. of Calif., Riverside, California, 2005.

Small, E. E.: Climatic controls on diffuse groundwater recharge in semiarid environments of the southwestern United States, Water Resour. Res., 41, W04012, doi:10.1029/2004WR003193, 2005.

Thompson, S. L. and Pollard, D.: A global climate model (GENESIS) with a land-surface transfer scheme (LSX), Part I: present climate simulation, J. Climate, 8, 732-761, 1995a.

Thompson, S. L. and Pollard, D.: A global climate model (GENESIS) with a land-surface transfer scheme (LSX), Part II: $\mathrm{CO}_{2}$ sensitivity, J. Climate, 8, 1104-1121, 1995b.

van Dam, J. D. and Feddes, R. A.: Numerical simulation of infiltration, evaporation and shallow groundwater levels with the Richards equation, J. Hydrol., 233, 72-85, 2000.

van Genuchten, M. T.: A closed-form equation for predicting the hydraulic conductivity of unsaturated soils, Soil Sci. Soc. Am. J., 44, 892-898, 1980.

Vervoort, R. W. and van der Zee, S. E. A. T. M.: Simulating the effect of capillary flux on the soil water balance in a stochastic ecohydrological framework, Water Resour. Res., 44, W08425, doi:10.1029/2008WR006889, 2008.

Wang, T., Zlotnik, V., Wedin, D., and Wally, K.D.: Spatial trends in saturated hydraulic conductivity of vegetated dunes in the $\mathrm{Ne}$ braska Sandhills: effects of depth and topography, J. Hydrol. 349, 88-97, doi:10.1016/j.jhydrol.2007.10.027, 2008.

Wang, T., Istanbulluoglu, E., Lenters, J. D., and Scott, D.: On the role of groundwater and soil texture in the regional water balance: An investigation of the Nebraska Sand Hills, USA, Water Resour. Res., 45, W10413, doi:10.1029/2009WR007733, 2009a.

Wang, T., Zlotnik, V. A., Simunek, J., and Schaap, M. G.: Using pedotransfer functions in vadose zone models for estimating groundwater recharge in semiarid regions, Water Resour. Res., 45, W04412, doi:10.1029/2008WR006903, 2009 b.

Warrick, A. W.: Additional solutions for steady-state evaporation from a shallow water table, Soil Sci., 146, 63-66, 1988.

Warrick, A. W.: Soil water dynamics, Oxford University Press, New York, 2003.

Yeh, P. J.-F. and Eltahir, E. A. B.: Representation of water table dynamics in a land surface scheme, part I: Model development, J. Climate, 18, 1861-1880, 2005.

York, J. P., Person, M., Gutowski, W. J., and Winter, T. C.: Putting aquifers into atmospheric simulation models: An example from Mill Creek Watershed, northeastern Kansas, Adv. Water Resour., 25, 221-238, 2002.

Zeng, X. and Decker, M.: Improving the numerical solution of soil moisture-based Richards equation for land models with a deep or shallow water table, J. Hydromet., 10, 308-319, 2009. 
Zhang, L., Potter, N., Hickel, K., Zhang, Y., and Shao, Q.: Water balance modeling over variable time scales based on the Budyko framework - model development and testing, J. Hydrol., 360, 117-131, 2008.
Zlotnik, V. A., Wang, T., Nieber, J. L., and Simunek, J. A.: Verification of numerical solutions of the Richards equation using a traveling wave solution, Adv. Water Resour., 30, 1973-1980, doi:10.1016/j.advwatres.2007.03.008, 2007. 